薄肉連続曲線枌橋の立体的解 析*

要 旨 各支間において橋軸が円弧状を呈し，中間支 点上で相接続する曲線線形を有する任意スパン数の連続 曲線桁橋に関して構造解析を行なった。

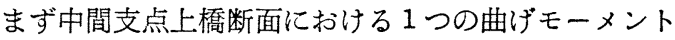
と 1 つ曲げねじりモーメントを未知量とする弾性方程 式を組立てた。つぎに支間の任意断面における断面力と 変形量についての解を, その支間を単純桁橋とみなした ときの荷重による值と, 支点モーメントによる值との和 として与えた。さらに 3 スパン連続合成 2 箱桁橋につい て, 数值計算を行ない各種断面力および変形量に関する 影響線を明らかにした。

\section{1. 緒言}

単純支持形式の曲線析橋においては，位置の不安定す なわち転倒の問題が起こりうることが容易に推察され る。安定性を確保するという点のみならず, 経済的設計 のためにも曲線析橋を連続形式にする方が望ましい。

そこで本文では，円弧と直線とが混在する軸線形状を もつ連続曲線桁橋について薄肉構造理論による立体的解 析を行なう。すでに文献 3)，4）の解析および数值計 算結果から明らかなように，曲線桁橋が鉛直荷重を受け た場合には，橋断面は曲率中心のまわりの回転をふくむ ような変位を行なう。したがって一般にたわみは直線桁 の場合に比してかなり大きくなる。それで横熬材(横析， 隔板, 横構, 対傾構, 床板など) が橋断面の変形に対し, ある程度の剛性を有する場合について，横县材の剛性を 無限大と考えて, 橋断面内の断面力や変形量に関する解 式を求める。曲線桁橋について橋断面形状不変の仮定の もとに，一体とする橋断面全体に生ずる断面力と変形量 を対象として問題を解決することが簡単で合理的な結果 を与えうるものと考える。

本文中特に説明がない記号については，文献 1)，2) を参照されたい。

\section{2. 連続曲線箱桁槅のひずみエネルギー}

一般の荷重状態において，連続曲線枌橋に生ずるひず みエネルギー I は次式で表わされる。

* 昭和 35 年度 土木学会関西支部年次学術講演会に発表 昭. 35.11

** 正員 工博 京都大学教授 工学部土木工学教室

*** 正員 工博 大阪市立大学助教授 工学部土木工学教室

$\begin{array}{llll}\text { 小 } & \text { 西 } & \text { 一 } & \text { 郎** } \\ \text { 小 } & \text { 松 } & \text { 定 } & \text { 夫*** }\end{array}$

$$
\Pi=\sum_{m} \frac{1}{2} \int_{0}^{\Phi_{m}} \int_{F_{m}}\left(\frac{\sigma^{2}}{E}+\frac{\tau^{2}}{G}\right) \rho_{m} d F_{m} d \varphi_{m}
$$

ここに $\sum_{m}$ は連続曲線桁橋の全橋長にわたって総和す るととを意味する。以下添字 $m$ は第 $m$ スパン断面に 関する量を表わす。

式（1）中に応力公式 [文献 3) 式 (51)，(53)] を代 入すれば，整とんののち，次式をうる。

$$
\begin{aligned}
& \Pi=\sum_{m}-\frac{R_{m}}{2} \int_{0}^{\Phi_{m}}\left\{\frac{1}{E_{s}}\left(\frac{M_{y m^{2}}}{I_{y m}{ }^{\prime}}+\frac{M_{w m}{ }^{2}}{C_{w m}}\right)\right. \\
& \left.+\frac{1}{G_{s}}\left(\frac{T_{s m^{2}}}{J_{m}}+\frac{\bar{Q}_{m}{ }^{2}}{\underline{F_{s m}{ }^{\prime}}}+\frac{Z_{m}}{C_{w m}{ }^{2}} T_{w m}{ }^{2}\right)\right\} d \varphi_{m} \\
& \text {........................................ (2) } \\
& \text { ここに, } Z=\int_{F} q^{* 2} \frac{n_{g}}{t} \frac{\rho}{R} d s \\
& \frac{1}{F_{s}^{\prime}}=\int_{F} \bar{q}_{b}{ }^{2} \frac{n_{g}}{t} \frac{\rho^{3}}{R^{3}} d s
\end{aligned}
$$

一般にアンダーラインの項は, 小さいので省略でき る。

\section{3. 連続曲線材橋の断面力}

図一1 亿示す連続曲線析橋の支点上断面に切断を入れ ると, 各支間で単純曲線桁橋の形式となり, 支点断面に

\section{図一1 連続曲線 桁橋}

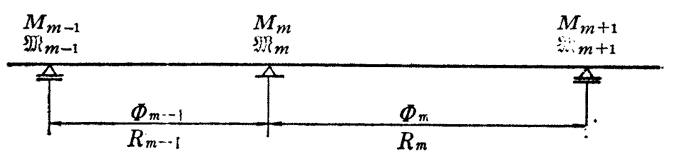

はそれぞれ1つずつの曲げモーメントと曲げねじりモー メントとが作朋する。今，第 $m$ 支点における両者の值 をそれぞれ $M_{m}$ および $\mathfrak{M}_{m}$ と記す。すると中心角 $\Phi_{m}$ をはさむ第 $m$ スパンにおいて, 支点より中心角 $\varphi_{m}$ に ある橋断面に生ずる断面力は次式で与えられる。式中， 添字 0 を付した量は，第 $m$ スパンを単純曲線析とみな したときの荷重による断面力を表わす。また $\varphi_{m}{ }^{\prime}=\Phi_{m}$ 一 $\varphi_{m}$ を表わす。

(1) 曲げモーメント $\boldsymbol{M}_{y m}$

$$
M_{y m}=M_{m 0}+M_{m} \frac{\sin \varphi_{m}^{\prime}}{\sin \Phi_{m}}+M_{m+1} \frac{\sin \varphi_{m}}{\sin \Phi_{m}}
$$

(2) 曲げねじりモーメント $\boldsymbol{M}_{w m}$

$$
M_{w m}=M_{m 0}+\mathfrak{M}_{m} \frac{\sinh \alpha_{m} \varphi_{m}{ }^{\prime}}{\sinh \alpha_{m} \Phi_{m}}+\mathfrak{M}_{m+1} \frac{\sinh \alpha_{m} \varphi_{m}}{\sinh \alpha_{m} \Phi_{m}}
$$




$$
\begin{aligned}
& +\frac{R_{m}}{\alpha_{m}{ }^{2}+1}\left\{M_{m}\left[\frac{\sin \varphi_{m}^{\prime}}{\sin \Phi_{m}}-\frac{\sinh \alpha_{m} \varphi_{m}{ }^{\prime}}{\sinh \alpha_{m} \Phi_{m}}\right]\right. \\
& \left.+M_{m+1}\left[\frac{\sin \varphi_{m}}{\sin \Phi_{m}}-\frac{\sinh \alpha_{m} \varphi_{m}}{\sinh \alpha_{m} \Phi_{m}}\right]\right\} \quad \cdots \cdots(6)
\end{aligned}
$$

\section{(3) St. Venant ねじりモーメント $\boldsymbol{T}_{s m}$}

$$
\begin{aligned}
& T_{s m}=T_{s m 0}+\frac{\mathfrak{M}_{m}}{R_{m}}\left(\frac{1}{\Phi_{m}}-\frac{\alpha_{m} \cos \mathrm{h} \alpha_{m} \varphi_{m}^{\prime}}{\left.\sinh \frac{\alpha_{m} \Phi_{m}}{\alpha}\right)}\right. \\
& +\frac{\mathfrak{M}_{m+1}}{R_{m}}\left(\frac{\alpha_{m} \cosh \alpha_{m} \varphi_{m}}{\sinh \alpha_{m} \Phi_{m}}-\frac{1}{\Phi_{m}}\right) \\
& +M_{m}\left[\frac{1}{\alpha_{m}{ }^{2}+1}\left(\alpha_{m}{ }^{2} \frac{\cos \varphi_{m}^{\prime}}{\sin \Phi_{m}}+\alpha_{m} \frac{\cosh \alpha_{m} \varphi_{m}{ }^{\prime}}{\sinh \alpha_{m} \Phi_{m}}\right)\right. \\
& \left.-\frac{1}{\Phi_{m}}\right]+M_{m+1}\left[\frac{1}{\Phi_{m}}-\frac{1}{\alpha_{m}{ }^{2}+1}-\left(\alpha_{m}{ }^{2} \frac{\cos \varphi_{m}}{\sin \Phi_{m}}\right.\right. \\
& \left.\left.+\alpha_{m} \frac{\cosh \alpha_{m} \varphi_{m}}{\sinh \alpha_{m} \Phi_{m}}\right)\right] \text {. }
\end{aligned}
$$

\section{(4) 2 次ねじりモーメント $\boldsymbol{T}_{w m}$}

$$
\begin{aligned}
& T_{w m}=T_{w m 0}+\frac{1}{R_{m}}\left(\mathfrak{M}_{m} \frac{\alpha_{m} \cosh \alpha_{m} \varphi_{m}{ }^{\prime}}{\sinh \alpha_{m} \Phi_{m}}\right. \\
& \left.-\mathfrak{M}_{m+1} \frac{\alpha_{m} \cosh \alpha_{m} \varphi_{m}}{\sinh \alpha_{m} \Phi_{m}}\right)+\frac{1}{\alpha_{m}{ }^{2}+1}\left[M _ { m } \left(\frac{\cos \varphi_{m}{ }^{\prime}}{\sin \Phi_{m}}\right.\right. \\
& \left.-\frac{\alpha_{m} \cosh \alpha_{m} \varphi_{m}^{\prime}}{\sinh \alpha_{m} \Phi_{m}}\right)-M_{m+1}\left(\frac{\cos \varphi_{m}}{\sin \Phi_{m}}\right. \\
& \left.\left.-\frac{\alpha_{m} \cosh \alpha_{m} \varphi_{m}}{\sinh \alpha_{m} \Phi_{m}}\right)\right]
\end{aligned}
$$

(5) 曲げせん断力 $\overline{\boldsymbol{Q}}_{m}$

$$
\overline{\boldsymbol{Q}}_{m}=\overline{\boldsymbol{Q}}_{m 0}-\frac{1}{R_{0 m}}\left(M_{m} \frac{\cos \varphi_{m}^{\prime}}{\sin \Phi_{m}}-M_{m+1} \frac{\cos \varphi_{m}}{\sin \Phi_{m}}\right)
$$

\section{（6） 合ねじりモーメント $\boldsymbol{T}_{m}$}

$$
\begin{gathered}
T_{m}=T_{m 0}+\frac{1}{l_{m}}\left(\mathfrak{M}_{m}-\mathfrak{M}_{m+1}\right)+M_{m}\left(\frac{\cos \varphi_{m}^{\prime}}{\sin \Phi_{m}}\right. \\
\left.-\frac{1}{\Phi_{m}}\right)+M_{m+1}\left(\frac{1}{\Phi_{m}}-\frac{\cos \varphi_{m}}{\sin \Phi_{m}}\right) \cdots \cdots \cdots(10)
\end{gathered}
$$

\section{4. 連続曲線桁橋の弾性方程式}

さて支点モーメント $M_{m}$ および $\mathfrak{M}_{m}$ を求めるため, 桁橋の全系に最小仕事の原理を適用すれば，

$$
\frac{\partial \Pi}{\partial M_{m}}=0, \quad \frac{\partial \Pi}{\partial \mathfrak{M}_{m}}=0
$$

上式の $I I$ に式 (2) を代入し，さらに断面力の公式 (5)〜(9)を用いて計算を行なえば，末知量 $M_{m}, \mathfrak{M}_{m}$ に 関する連立方程式をうる。

$$
\begin{aligned}
& a_{m, m-1} M_{m-1}+a_{m m} M_{m}+a_{m, m+1} M_{m+1}+b_{m, m-1} \mathfrak{M}_{m-1} \\
&+b_{m m} \mathfrak{M}_{m}+b_{m, m+1} \mathfrak{M}_{m+1}=-L_{m} \\
& b_{m, m-1} M_{m-1}+b_{m m} M_{m}+b_{m, m+1} M_{m+1}+d_{m, m-1} \mathfrak{M}_{m-1} \\
&+d_{m m} \mathfrak{M}_{m}+d_{m, m+1} \mathfrak{M}_{m+1}=-N_{m} \\
&(m=1,2, \cdots \cdots, n-1) \cdots \cdots \cdots \cdots(11)
\end{aligned}
$$

両端支点で単純支持になっている場合には，

$$
M_{0}=M_{n}=0, \quad \mathfrak{M}_{0}=\mathfrak{M}_{n}=0
$$

連立方程式 (11) に現われる係数 $a, b$ および $d$ はつ ぎのように同形の式で与えられる。

$$
a_{m m}=\sum_{j=m-1}^{m}[a]_{m j}
$$

そして,

$$
\begin{aligned}
& {[a]_{m j}=A\left(\Phi_{j}\right) \frac{R_{j}}{E_{s} I_{y j^{\prime}}}+B\left(\Phi_{j}\right) \frac{R_{j}{ }^{3}}{E_{s} C_{w j}}} \\
& +C\left(\Phi_{j}\right) \frac{R_{j}}{G_{s} J_{j}}+D\left(\Phi_{j}\right) \frac{R_{j} Z_{j}}{G_{s} C_{w j^{2}}} \\
& +E\left(\Phi_{j}\right) \frac{1}{G_{s} F_{s j}{ }^{\prime} R_{j}} \cdots \cdots \ldots \ldots \ldots \ldots \ldots \ldots \ldots \ldots \ldots \ldots \ldots \ldots
\end{aligned}
$$

また，

$$
\begin{aligned}
& a_{m, m-1}=A^{\prime}\left(\Phi_{m-1}\right) \frac{R_{m-1}}{E_{s} I_{y, m-1}} \\
& +B^{\prime}\left(\Phi_{m-1}\right) \frac{R_{m-1}{ }^{3}}{E_{s} C_{w, m-1}}+C^{\prime}\left(\Phi_{m-1}\right) \frac{R_{m-1}}{G_{s} J_{m-1}} \\
& +D^{\prime}\left(\Phi_{m-1}\right) \frac{R_{m-1} Z_{m-1}}{G_{s} C_{w, m-1}{ }^{2}} \\
& \underline{-E^{\prime}\left(\Phi_{m-1}\right) \frac{1}{G_{s} F_{s, m-1} R_{m-1}}} \\
& a_{m, m+1}=A^{\prime}\left(\Phi_{m}\right) \frac{R_{m}}{E_{s} I_{y m^{\prime}}}+B^{\prime}\left(\Phi_{m}\right) \frac{R_{m}{ }^{3}}{E_{s} C_{w m}} \\
& +C^{\prime}\left(\Phi_{m}\right) \frac{R_{m}}{G_{s} J_{m}}+\underline{D^{\prime}\left(\Phi_{m}\right) \frac{R_{m} Z_{m}}{G_{s} C_{w m}{ }^{2}}} \\
& \underline{-E^{\prime}\left(\Phi_{m}\right) \frac{1}{G_{s} F_{s m}^{\prime} R_{m}}}
\end{aligned}
$$

ことに,

$$
\begin{aligned}
& A\left(\varphi_{j}\right)=\frac{2 \varphi_{j}-\sin 2 \varphi_{j}}{4 \sin ^{2} \Phi_{j}} \\
& B\left(\varphi_{j}\right)=\frac{1}{\left(\alpha_{j}{ }^{2}+1\right)^{2}}\left[A\left(\varphi_{j}\right)-2 \mathfrak{U}\left(\varphi_{j}\right)+\mathfrak{B}\left(\varphi_{j}\right)\right] \\
& C\left(\varphi_{j}\right)=\frac{\alpha_{j}{ }^{2}}{\left(\alpha_{j}{ }^{2}+1\right)^{2}}\left[\alpha_{j}{ }^{2} E\left(\varphi_{j}\right)+2 \alpha_{j} \mathfrak{D}\left(\varphi_{j}\right)\right. \\
& \left.+\xi\left(\varphi_{j}\right)\right]-\frac{1}{\Phi_{j}}
\end{aligned}
$$

$$
\begin{aligned}
D\left(\varphi_{j}\right)= & \frac{1}{\left(\alpha_{j}{ }^{2}+1\right)^{2}}\left[E\left(\varphi_{j}\right)-2 \alpha_{j} \mathfrak{D}\left(\varphi_{j}\right)\right. \\
& \left.+\alpha_{j}{ }^{2} \xi\left(\varphi_{j}\right)\right] \ldots \ldots \ldots \ldots \ldots \ldots \ldots \ldots \ldots \ldots \ldots \ldots \ldots \ldots \ldots \ldots \ldots \ldots \ldots \ldots \ldots \ldots \ldots \\
E\left(\varphi_{j}\right)= & \frac{\sin 2 \varphi_{j}+2 \varphi_{j}}{4 \sin ^{2} \Phi_{j}} \ldots \ldots \ldots \ldots \ldots \ldots \ldots
\end{aligned}
$$

$$
B^{\prime}\left(\varphi_{j}\right)=\frac{1}{\left(\alpha_{j}^{2}+1\right)^{2}}\left[A^{\prime}\left(\varphi_{j}\right)-2 \mathfrak{U}^{\prime}\left(\varphi_{j}\right)+\mathfrak{B}^{\prime}\left(\varphi_{j}\right)\right]
$$

$$
\begin{aligned}
C^{\prime}\left(\varphi_{j}\right) & =\frac{-\alpha_{j}{ }^{2}}{\left(\alpha_{j}{ }^{2}+1\right)^{2}}\left[\alpha_{j}{ }^{2} E^{\prime}\left(\varphi_{j}\right)+2 \alpha_{j} \mathfrak{D}^{\prime}\left(\varphi_{j}\right)\right. \\
& \left.+\xi^{\prime}\left(\varphi_{j}\right)\right]+\frac{1}{\Phi_{j}} \cdots \cdots \ldots \ldots \ldots \ldots \ldots \ldots \ldots \ldots \ldots \ldots \ldots
\end{aligned}
$$

$$
\begin{aligned}
D^{\prime}\left(\varphi_{j}\right)= & \frac{1}{\left(\alpha_{j}^{2}+1\right)^{2}}\left[-E^{\prime}\left(\varphi_{j}\right)+2 \alpha_{j} \mathfrak{D}^{\prime}\left(\varphi_{j}\right)\right. \\
& \left.-\alpha_{j}{ }^{2} \xi^{\prime}\left(\varphi_{j}\right)\right] \cdots \cdots \cdots \cdots \cdots \cdots \cdots \cdots \cdots \cdots \cdots \cdots \cdots \cdots \cdots \cdots \cdots \\
E^{\prime}\left(\varphi_{j}\right)= & \frac{\sin ^{2} \varphi_{j}}{2 \sin \Phi_{j}}+E\left(\varphi_{j}\right) \cos \Phi_{j} \cdots \cdots \cdots \cdots \cdots
\end{aligned}
$$


さらに,

$$
\begin{aligned}
& \mathfrak{A}\left(\varphi_{j}\right)=\frac{\alpha_{j} \cosh \alpha_{j} \varphi_{j} \sin \varphi_{j}-\sinh \alpha_{j} \varphi_{j} \cos \varphi_{j}}{\left(\alpha_{j}^{2}+1\right) \sinh \alpha_{j} \Phi_{j} \sin \Phi_{j}} \\
& \mathscr{B}\left(\varphi_{j}\right)=\frac{\sinh 2 \alpha_{j} \varphi_{j}-2 \alpha_{j} \varphi_{j}}{4 \alpha_{j} \sin \mathrm{h}^{2} \alpha_{j} \Phi_{j}} \\
& \mathfrak{D}\left(\varphi_{j}\right)=\frac{\alpha_{j} \sinh \alpha_{j} \varphi_{j} \cos \varphi_{j}+\cosh \alpha_{j} \varphi_{j} \sin \varphi_{j}}{\left(\alpha_{j}^{2}+1\right) \sinh \alpha_{j} \Phi_{j} \sin \Phi_{j}} \\
& \xi\left(\varphi_{j}\right)=\frac{\sinh 2 \alpha_{j} \varphi_{j}+2 \alpha_{j} \varphi_{j}}{4 \alpha_{j} \sinh ^{2} \alpha_{j} \Phi_{j}} \\
& \frac{\sinh \alpha_{j} \Phi_{j}-\sinh \alpha_{j} \varphi_{j}{ }^{\prime} \cos \varphi_{j}-\alpha_{j} \cosh \alpha_{j} \varphi_{j}{ }^{\prime} \sin \varphi_{j}}{\left(\alpha_{j}{ }^{2}+1\right) \sinh \alpha_{j} \Phi_{j} \sin \Phi_{j}}
\end{aligned}
$$

$$
\mathfrak{B}^{\prime}\left(\varphi_{j}\right)=\frac{\sinh h^{2} \alpha_{j} \varphi_{j}}{2 \alpha_{j} \sinh \alpha_{j} \Phi_{j}}-\mathfrak{B}\left(\varphi_{j}\right) \cosh \alpha_{j} \Phi_{j}
$$

$$
\mathfrak{D}^{\prime}\left(\varphi_{j}\right)=
$$

$\underline{\alpha_{j} \sinh \alpha_{j} \varphi_{j} \cos \varphi_{j}{ }^{\prime}-\cosh \alpha_{j} \varphi_{j} \sin \varphi_{j}{ }^{\prime}+\sin \Phi_{j}}$ $\left(\alpha_{j}^{2}+1\right) \sinh \alpha_{j} \Phi_{j} \sin \Phi_{j}$

$$
\xi^{\prime}\left(\varphi_{j}\right)=\xi\left(\varphi_{j}\right) \cosh \alpha_{j} \Phi_{j}-\frac{\sinh ^{2} \alpha_{j} \varphi_{j}}{2 \alpha_{j} \sinh \alpha_{j} \Phi_{j}}
$$

つぎに,

$$
\begin{aligned}
& b_{m m}=\sum_{j=m-1}^{m}[b]_{m j} \\
& {[b]_{m j}=F\left(\Phi_{j}\right) \frac{R_{j}^{2}}{E_{s} C_{w j}}+G\left(\Phi_{j}\right) \frac{1}{G_{s} J_{j}}} \\
& +\underline{H\left(\Phi_{j}\right) \frac{Z_{j}}{G_{s} C_{w j}{ }^{2}}} \\
& b_{m, m-1}=F^{\prime}\left(\Phi_{m-1}\right) \frac{R_{m-1}^{2}}{E_{s} C_{w, m-1}}+G^{\prime}\left(\Phi_{m-1}\right) \frac{1}{G_{s} J_{m-1}} \\
& +H^{\prime}\left(\Phi_{m-1}\right) \frac{Z_{m-1}}{G_{s} C_{w, m-1}{ }^{2}} \\
& b_{m, m+1}=F^{\prime}\left(\Phi_{m}\right) \frac{R_{m}{ }^{2}}{E_{s} C_{w m}}+G^{\prime}\left(\Phi_{m}\right) \frac{1}{G_{s} J_{m}} \\
& +H^{\prime}\left(\Phi_{m}\right) \frac{Z_{m}}{G_{s} C_{w n}^{2}} \\
& F\left(\varphi_{j}\right)=\frac{\mathfrak{A}\left(\varphi_{j}\right)-\mathfrak{B}\left(\varphi_{j}\right)}{\alpha_{j}{ }^{2}+1} \\
& G\left(\varphi_{j}\right)=\frac{-\alpha_{j}^{2}}{\alpha_{j}^{2}+1}\left[\alpha_{j} \mathfrak{D}\left(\varphi_{j}\right)+\xi\left(\varphi_{j}\right)\right]+\frac{1}{\Phi_{j}} \cdots \\
& H\left(\varphi_{j}\right)=\frac{\alpha_{j}}{\alpha_{j}^{2}+1}\left[\mathfrak{D}\left(\varphi_{j}\right)-\alpha_{j} \xi\left(\varphi_{j}\right)\right] \\
& F^{\prime}\left(\varphi_{j}\right)=\frac{1}{\alpha_{j}^{2}+1}\left[\mathfrak{A}^{\prime}\left(\varphi_{j}\right)-\mathfrak{B}^{\prime}\left(\varphi_{j}\right)\right] \\
& G^{\prime}\left(\varphi_{j}\right)=\frac{\alpha_{j}^{2}}{\alpha_{j}^{2}+1}\left[\alpha_{j} \mathfrak{D}^{\prime}\left(\varphi_{j}\right)+\xi^{\prime}\left(\varphi_{j}\right)\right]-\frac{1}{\Phi_{j}} \\
& H^{\prime}\left(\varphi_{j}\right)=\frac{\alpha_{j}}{\alpha_{j}^{2}+1}\left[-\mathfrak{D}^{\prime}\left(\varphi_{j}\right)+\alpha_{j} \xi^{\prime}\left(\varphi_{j}\right)\right]
\end{aligned}
$$

最後に，

$$
d_{m m}=\sum_{j=m-1}^{m}[d]_{m j}
$$

$$
\begin{aligned}
& {[d]_{m j}=\mathfrak{B}\left(\Phi_{j}\right) \frac{R_{j}}{E_{s} C_{w j}}+K\left(\Phi_{j}\right) \frac{1}{G_{s} J_{j} R_{j}}} \\
& +\frac{\alpha_{j}^{2}}{R_{j}} \xi\left(\Phi_{j}\right) \frac{Z_{j}}{G_{s} C_{w j}^{2}} \\
& d_{m, m-1}=\mathfrak{B}^{\prime}\left(\Phi_{m-1}\right) \frac{R_{m-1}}{E_{s} C_{w, m-1}} \\
& +K^{\prime}\left(\Phi_{m-1}\right) \frac{1}{G_{s} J_{m-1} R_{m-1}} \\
& -\frac{\alpha_{m-1}^{2}}{R_{m-1}} \xi^{\prime}\left(\Phi_{m-1}\right) \frac{Z_{m-1}}{G_{s} C_{w}^{2}, m-1} \\
& d_{m, m+1}=\mathfrak{B}^{\prime}\left(\Phi_{m}\right) \frac{R_{m}}{E_{s} C_{w m}}+K^{\prime}\left(\Phi_{m}\right) \frac{1}{G_{s} J_{m} R_{m}} \\
& -\frac{\alpha_{m}^{2}}{R_{m}} \xi^{\prime}\left(\Phi_{m}\right) \frac{Z_{m}}{G_{s} C_{w m}^{2}}
\end{aligned}
$$

ことに

$$
\begin{aligned}
& K\left(\varphi_{j}\right)=\alpha_{j}{ }^{2} \xi\left(\varphi_{j}\right)-\frac{1}{\Phi_{j}} \cdots \\
& K^{\prime}\left(\varphi_{j}\right)=-\alpha_{j}{ }^{2} \xi^{\prime}\left(\varphi_{j}\right)+\frac{1}{\Phi_{j}}
\end{aligned}
$$

式 (14)，(15)，(36)，(37)，(46) および (47) から,

$a_{m, m+1}=a_{m+1, m}, b_{m, m+1}=b_{m+1, m}, d_{m, m+1}=d_{m+1, m}$ なる関係が成立することを知る。

\section{5. 弾性方程式の荷重項}

代表的な鉛直荷重状態に対し，弾性方程式の右辺の荷 重項をつぎのようにえた。

\section{（1）等分布荷重}

荷重強度 $p_{j}$ なる等分布荷重が第 $j$ スパンに作用す る場合には, 荷重項 $L_{m j}$ および $N_{m j}$ はつぎのように なる。

$$
\begin{aligned}
L_{m j} & =p_{j}\left\{\mathfrak{\Omega}_{1 j} A_{l} * \frac{R_{j}}{E_{s} I_{y j}{ }^{\prime}}+\left[\mathfrak{Q}_{1 j} B_{l_{1}} *\right.\right. \\
& \left.+\mathfrak{\Omega}_{2 j} B_{l_{2}} *\right] \frac{R_{j}{ }^{3}}{E_{s} C_{w j}}+\left[\mathfrak{\Omega}_{1 j} C_{l_{1}} *+\mathfrak{\Omega}_{2 j} C_{l_{2}} *\right] \frac{R_{j}}{G_{s} J_{j}} \\
+ & \left.+\mathfrak{\Omega}_{1 j} D_{l_{1}} *+\mathfrak{\Omega}_{2 j} D_{l_{2}} *\right] \frac{Z_{j} R_{j}}{G_{s} C_{w j}{ }^{2}}+\mathfrak{\Omega}_{1 j} E_{l} * \frac{1}{G_{s} F_{s j}{ }^{\prime} R_{j}}
\end{aligned}
$$

ここに,

$$
\begin{aligned}
A_{l} *= & A\left(\Phi_{j}\right)+A^{\prime}\left(\Phi_{j}\right)-\frac{1-\cos \Phi_{j}}{\sin \Phi_{j}} \cdots \cdots \cdots(51) \\
B_{l_{1}} *= & \frac{1}{\left(\iota_{j}^{2}+1\right)^{2}}\left[A\left(\Phi_{j}\right)+A^{\prime}\left(\Phi_{j}\right)-2 \mathfrak{A}\left(\Phi_{j}\right)\right. \\
& \left.-2 \mathfrak{U}^{\prime}\left(\Phi_{j}\right)+\mathfrak{B}\left(\Phi_{j}\right)+\mathfrak{B}^{\prime}\left(\Phi_{j}\right)\right] \cdots \cdots(52) \\
B_{l_{2}} *= & \frac{1}{\alpha_{j}{ }^{2}\left(\alpha_{j}^{2}+1\right)}\left[\mathfrak{A}\left(\Phi_{j}\right)+\mathfrak{U}^{\prime}\left(\Phi_{j}\right)-\frac{1-\cos \Phi_{j}}{\sin \Phi_{j}}\right. \\
& \left.-\mathfrak{B}\left(\Phi_{j}\right)-\mathfrak{B}^{\prime}\left(\Phi_{j}\right)+\frac{\cosh \alpha_{j} \Phi_{j}-1}{\alpha_{j} \sinh \alpha_{j} \Phi_{j}}\right] \cdots(53) \\
C_{l_{1}} *= & \frac{\alpha_{j}^{2}}{\left(\alpha_{j}^{2}+1\right)^{2}}\left\{\alpha_{j}^{2}\left[E\left(\Phi_{j}\right)-E^{\prime}\left(\Phi_{j}\right)\right]\right. \\
& \left.+2 \alpha_{j}\left[\mathfrak{D}\left(\Phi_{j}\right)-\mathfrak{D}^{\prime}\left(\Phi_{j}\right)\right]+\xi\left(\Phi_{j}\right)-\xi^{\prime}\left(\Phi_{j}\right)\right\}
\end{aligned}
$$




$$
\begin{aligned}
& C_{l_{2}}{ }^{*}=\frac{1}{\alpha_{j}{ }^{2}+1}\left\{\alpha_{j}^{2}\left(\frac{\Phi_{j}}{2}-\frac{1-\cos \Phi_{j}}{\sin \Phi_{j}}\right)+\alpha_{j}\left[\mathscr{D}^{\prime}\left(\Phi_{j}\right)\right.\right. \\
& \left.-\mathscr{D}\left(\Phi_{j}\right)\right]+\xi^{\prime}\left(\Phi_{j}\right)-\xi\left(\Phi_{j}\right)+\frac{\Phi_{j}}{2} \\
& \left.-\frac{\cosh \alpha_{j} \Phi_{j}-1}{\alpha_{j} \sinh \alpha_{j} \Phi_{j}}\right\} \\
& \underline{D_{l_{1}} *}=\frac{1}{\left(\alpha_{j}^{2}+1\right)^{2}}\left\{\alpha_{j}^{2}\left[\xi\left(\Phi_{j}\right)-\xi^{\prime}\left(\Phi_{j}\right)\right]\right. \\
& \left.+2 \alpha_{j}\left[\mathscr{D}^{\prime}\left(\Phi_{j}\right)-\mathfrak{D}\left(\Phi_{j}\right)\right]+E\left(\Phi_{j}\right)-E^{\prime}\left(\Phi_{j}\right)\right\} \\
& \underline{D_{l_{2}}}=\frac{-1}{\left(\alpha_{j}^{2}+1\right) \alpha_{j}}\left\{\alpha_{j}\left[\xi\left(\Phi_{j}\right)-\xi^{\prime}\left(\Phi_{j}\right)\right]\right. \\
& \left.+\mathfrak{D}^{\prime}\left(\Phi_{j}\right)-\mathfrak{D}\left(\Phi_{j}\right)\right\} \\
& \underline{E_{l} *}=E\left(\Phi_{j}\right)-E^{\prime}\left(\Phi_{j}\right) \\
& N_{m j}=p_{j}\left\{\left[\Omega_{1 j} B_{n 1} *+\Omega_{2 j} B_{n 2} *\right] \frac{R_{j}^{2}}{E_{s} C_{w j}}+\left[\Omega_{1 j} C_{n 1} *\right.\right. \\
& \left.+\Omega_{2 j} C_{n 2} *\right] \frac{1}{G_{s} J_{j}}+\left[\Omega_{1 j} D_{n 1} *\right. \\
& +\underline{\left.\Omega_{2 j} D_{n 2} *\right] \frac{Z_{j}}{G_{s} C_{w j}{ }^{2}}}
\end{aligned}
$$

こてに,

$$
\begin{aligned}
B_{n 1}{ }^{*}= & \frac{1}{\alpha_{j}^{2}+1}\left[\mathfrak{A}\left(\Phi_{j}\right)+\mathfrak{H}^{\prime}\left(\Phi_{j}\right)-\mathfrak{B}\left(\Phi_{j}\right)-\mathfrak{B}^{\prime}\left(\Phi_{j}\right)\right] \\
& \ldots \ldots \ldots \ldots \ldots \ldots \ldots(60) \\
L_{m j}= & \frac{W_{j}}{R_{0 j}}\left\{\mathfrak{Q}_{2 j} A A_{l} * \frac{R_{j}}{E_{s} I_{y j^{\prime}}}+\left(\Omega_{2 j} B_{l 2} * *+\Omega_{3 j} B_{l_{3}} * *\right.\right. \\
& \left.\left.+\Omega_{3 j} D_{l_{3}} * *\right) \frac{Z_{j} R_{j}}{G_{s} C_{w j^{2}}}+\Omega_{2 j} E_{l} * * \frac{1}{G_{s} F_{s j^{\prime} R_{j}}}\right\}
\end{aligned}
$$$$
L_{m j}=\frac{W_{j}}{R_{0 j}}\left\{\mathfrak{Q}_{2 j} A_{l} * * \frac{R_{j}}{E_{s} I_{y j}{ }^{\prime}}+\left(\mathfrak{\Omega}_{2 j} B_{l_{2}}{ }^{* *}+\mathfrak{\Omega}_{3 j} B_{l_{3}} * *\right) \frac{R_{j}{ }^{3}}{E_{s} C_{w j}}+\left(\mathfrak{\Omega}_{2 j} C_{l_{2}}{ }^{* *}+\Omega_{3 j} C_{l_{3}} * *\right) \frac{R_{j}}{G_{s} J_{j}}+\left(\mathfrak{\Omega}_{2 j} D_{l_{2}} * *\right.\right.
$$

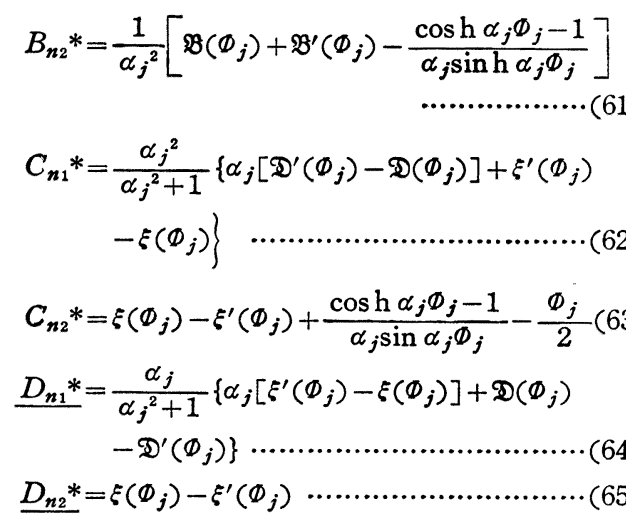

\section{（2）軸方向線荷重}

ての荷重状態に対しては，（1）の等分布荷重の場合の 荷重項 $L_{m j}$ と $N_{m j}$ において, $\mathbb{1}_{1 j} \rightarrow \bar{R}_{j}{ }^{2}, \Omega_{2 j} \rightarrow \bar{R}_{j} R_{0 j}$, $p_{j} \rightarrow W_{j}$ と置きかえれば，そのまま利用できる。

\section{（3）横方向線荷重}

半径方向に単位長さあたり $W_{j}$ なる強度の線荷重が 作用する場合について考える。載荷位置を $\varphi_{j}=\psi_{j}$ と する。

とてr,

(i) $j=m$ に対しては,

$A_{l}{ }^{* *}=A^{\prime}\left(\psi_{m}\right) \cdot \sin \psi_{m}^{\prime}+A\left(\psi_{m}{ }^{\prime}\right) \cdot \sin \psi_{m}$

$B_{l_{2}}{ }^{* *}=\frac{1}{\left(\alpha_{m}^{2}+1\right)^{2}}\left\{\alpha_{m}\left\{\sinh \alpha_{m} \psi_{m}{ }^{\prime} \cdot\left[\mathfrak{A}^{\prime \prime}\left(\psi_{m}\right)-\mathfrak{B}^{\prime}\left(\psi_{m}\right)\right]+\sinh \alpha_{m} \psi_{m} \cdot\left[\mathfrak{A}\left(\psi_{m}^{\prime}\right)-\mathfrak{B}\left(\psi_{m}^{\prime}\right)\right]\right\}\right.$

$\left.+\sin \psi_{m}^{\prime} \cdot\left[A^{\prime}\left(\psi_{m}\right)-\mathfrak{A}^{\prime}\left(\psi_{m}\right)\right]+\sin \psi_{m} \cdot\left[A\left(\psi_{m}^{\prime}\right)-\mathfrak{A}\left(\psi_{m}^{\prime}\right)\right]\right\}$

$B_{l 3} * *=\frac{1}{\left(\alpha_{m}^{2}+1\right) \alpha_{m}}\left\{\sinh \alpha_{m} \psi_{m}^{\prime}\left[\mathfrak{B}^{\prime}\left(\psi_{m}\right)-\mathfrak{A}^{\prime \prime}\left(\psi_{m}\right)\right]+\sinh \alpha_{m} \psi_{m} \cdot\left[\mathfrak{B}\left(\psi_{m}^{\prime}\right)-\mathfrak{A}\left(\psi_{m}^{\prime}\right)\right]\right\}$

$C_{l_{2}} * *=\frac{\alpha_{m}{ }^{3}}{\left(\alpha_{m}{ }^{2}+1\right)^{2}}\left\{\sinh \alpha_{m} \psi_{m}^{\prime}\left[\alpha_{m} \mathfrak{D}^{\prime}\left(\psi_{m}\right)+\xi^{\prime}\left(\psi_{m}\right)\right]-\sinh \alpha_{m} \psi_{m}\left[\alpha_{m} \mathfrak{D}\left(\psi_{m}^{\prime}\right)+\xi\left(\psi_{m}{ }^{\prime}\right)\right]\right.$

$\left.-\sin \psi_{m}^{\prime}\left[\alpha_{m} E^{\prime}\left(\psi_{m}\right)+\mathfrak{D}^{\prime \prime}\left(\psi_{m}\right)\right]+\sin \psi_{m}\left[\alpha_{m} E\left(\psi_{m}^{\prime}\right)+\mathfrak{D}\left(\psi_{m}^{\prime}\right)\right]\right\}$

$C_{l_{3}}{ }^{* *}=\frac{\alpha_{m}}{\alpha_{m}^{2}+1}\left\{\sinh \alpha_{m} \psi_{m} \cdot\left[\alpha_{m} \mathfrak{D}\left(\psi_{m}^{\prime}\right)+\xi\left(\psi_{m}^{\prime}\right)\right]-\sinh \alpha_{m} \psi_{m}^{\prime} \cdot\left[\alpha_{m} \mathscr{D}^{\prime}\left(\psi_{m}\right)+\xi^{\prime}\left(\psi_{m}\right)\right]-\left(\alpha_{m} \frac{\sin \psi_{m}{ }^{\prime}}{\sin \Phi_{m}}\right.\right.$

$\left.\left.+\frac{1}{\alpha_{m}} \frac{\sinh \alpha_{m} \psi_{m}^{\prime}}{\sinh \alpha_{m} \Phi_{m}}\right)\right\}+\frac{\psi_{m}^{\prime}}{\Phi_{m}}$

$\underline{D_{l_{2}} * *}=\frac{1}{\left(\alpha_{m}{ }^{2}+1\right)^{2}}\left\{\alpha_{m}^{2}\left\{\sinh \alpha_{m} \psi_{m} \cdot\left[\mathfrak{D}\left(\psi_{m}{ }^{\prime}\right)-\alpha_{m} \xi\left(\psi_{m}{ }^{\prime}\right)\right]-\sinh \alpha_{m} \psi_{m}{ }^{\prime} \cdot\left[\mathfrak{D}^{\prime}\left(\psi_{m}\right)-\alpha_{m} \xi^{\prime}\left(\psi_{m}\right)\right]\right\}\right.$ $\left.+\sin \psi_{m}\left[E\left(\psi_{m}^{\prime}\right)-\alpha_{m} \mathfrak{D}\left(\psi_{m}^{\prime}\right)\right]-\sin \psi_{m}{ }^{\prime} \cdot\left[E^{\prime}\left(\psi_{m}\right)-\alpha_{m} \mathfrak{D}^{\prime \prime}\left(\psi_{m}\right)\right]\right\}$

$\underline{D_{3} * *}=\frac{1}{\alpha_{m}^{2}+1}\left\{\sinh \alpha_{m} \psi_{m}^{\prime}\left[\mathfrak{D}^{\prime}\left(\psi_{m}\right)-\alpha_{m} \xi^{\prime}\left(\psi_{m}\right)\right]-\sinh \alpha_{m} \psi_{m}\left[\mathfrak{D}\left(\psi_{m}^{\prime}\right)-\alpha_{m} \xi\left(\psi_{m}^{\prime}\right)\right]\right\}$

$\underline{E_{l} * *}=E\left(\psi_{m}^{\prime}\right) \sin \psi_{m}-E^{\prime}\left(\psi_{m}\right) \sin \psi_{m}^{\prime}$

(ii) $j=m-1$ に対して,

$A_{l} * *=A\left(\psi_{m-1}\right) \sin \psi_{m-1}{ }^{\prime}+A^{\prime}\left(\psi_{m-1}{ }^{\prime}\right) \sin \psi_{m-1}$

$B_{l 2} * *=\frac{1}{\left(\alpha_{m-1}^{2}+1\right)^{2}}\left\{\alpha_{m-1}\left\{\sinh \alpha_{m-1} \psi_{m-1}^{\prime} \cdot\left[\mathfrak{A}\left(\psi_{m-1}\right)-\mathfrak{B}\left(\psi_{m-1}\right)\right]+\sinh \alpha_{m-1} \psi_{m-1}\left[\mathfrak{A}^{\prime \prime}\left(\psi_{m-1}{ }^{\prime}\right)\right.\right.\right.$

$\left.\left.\left.-\mathfrak{B}^{\prime}\left(\psi_{m-1}{ }^{\prime}\right)\right]\right\}+\sin \psi_{m-1}{ }^{\prime}\left[A\left(\psi_{m-1}\right)-\mathfrak{A}\left(\psi_{m-1}\right)\right]+\sin \psi_{m-1} \cdot\left[A^{\prime}\left(\psi_{m-1}{ }^{\prime}\right)-\mathfrak{A}^{\prime}\left(\psi_{m-1}{ }^{\prime}\right)\right]\right\}$ 
$B_{l 3} * *=\frac{1}{\left(\alpha_{m-1}^{2}+1\right) \alpha_{m-1}}\left\{\sinh \alpha_{m-1} \psi_{m-1}^{\prime} \cdot\left[\mathfrak{B}\left(\psi_{m-1}\right)-\mathfrak{X}\left(\psi_{m-1}\right)\right]+\sinh \alpha_{m-1} \psi_{m-1} \cdot\left[\mathfrak{B}^{\prime}\left(\psi_{m-1}^{\prime}\right)-\mathfrak{X}^{\prime \prime}\left(\psi_{m-1}^{\prime}\right)\right]\right\}$ $C_{l_{2}} * *=\frac{\alpha_{m-1}{ }^{3}}{\left(\alpha_{m-1}{ }^{2}+1\right)^{2}}\left\{\sinh \alpha_{m-1} \psi_{m-1} \cdot\left[\alpha_{m-1} \mathfrak{D}^{\prime}\left(\psi_{m-1}{ }^{\prime}\right)+\xi^{\prime}\left(\psi_{m-1}{ }^{\prime}\right)\right]-\sinh \alpha_{m-1} \psi_{m-1}{ }^{\prime} \cdot\left[\alpha_{m-1} \mathfrak{D}\left(\psi_{m-1}\right)\right.\right.$ $\left.\left.+\xi\left(\psi_{m-1}\right)\right]+\sin \psi_{m-1}^{\prime}\left[\alpha_{m-1} E\left(\psi_{m-1}\right)+\mathfrak{D}\left(\psi_{m-1}\right)\right]-\sin \psi_{m-1} \cdot\left[\alpha_{m-1} E^{\prime}\left(\psi_{m-1}^{\prime}\right)+\mathfrak{D}^{\prime \prime}\left(\psi_{m-1}^{\prime}\right)\right]\right\}$

$C_{l_{3}} * *=\frac{\alpha_{m-1}}{\alpha_{m-1}{ }^{2}+1}\left\{\sinh \alpha_{m-1} \psi_{m-1}{ }^{\prime} \cdot\left[\alpha_{m-1} \mathfrak{D}\left(\psi_{m-1}\right)+\xi\left(\psi_{m-1}\right)\right]-\sinh \alpha_{m-1} \psi_{m-1} \cdot\left[\alpha_{m-1} \mathfrak{D}^{\prime}\left(\psi_{m-1}\right)+\xi^{\prime}\left(\psi_{m-1}\right)\right]\right.$ $\left.-\left[\alpha_{m-1} \frac{\sin \psi_{m-1}}{\sin \Phi_{m-1}}+\frac{1}{\alpha_{m-1}} \frac{\sinh \alpha_{m-1} \psi_{m-1}}{\sinh \alpha_{m-1} \Phi_{m-1}}\right]\right\}+\frac{\psi_{m-1}}{\Phi_{m-1}}$

$\underline{D_{l 2} * *}=\frac{1}{\left(\alpha_{m-1}{ }^{2}+1\right)^{2}}\left\{\alpha_{m-1}{ }^{2}\left\{\sinh \alpha_{m-1} \psi_{m-1}{ }^{\prime}\left[\mathfrak{D}\left(\psi_{m-1}\right)-\alpha_{m-1} \xi\left(\psi_{m-1}\right)\right]+\sinh \alpha_{m-1} \psi_{m-1} \cdot\left[\alpha_{m-1} \xi^{\prime}\left(\psi_{m-1}{ }^{\prime}\right)\right.\right.\right.$ $\left.\left.\left.-\mathfrak{D}^{\prime}\left(\psi_{m-1}^{\prime}\right)\right]\right\}+\sin \psi_{m-1}{ }^{\prime}\left[E\left(\psi_{m-1}\right)-\alpha_{m-1} \mathfrak{D}\left(\psi_{m-1}\right)\right]+\sin \psi_{m-1}\left[\alpha_{m-1} \mathfrak{D}^{\prime \prime}\left(\psi_{m-1}{ }^{\prime}\right)-E^{\prime}\left(\psi_{m-1}^{\prime}\right)\right]\right\}$

$\underline{D_{l 3} * *}=\frac{1}{\alpha_{m-1}^{2}+1}\left\{\sinh \alpha_{m-1} \psi_{m-1}^{\prime}\left[\alpha_{m-1} \xi\left(\psi_{m-1}\right)-\mathfrak{D}\left(\psi_{m-1}\right)\right]+\sinh \alpha_{m-1} \psi_{m-1}\left[\mathfrak{D}^{\prime}\left(\psi_{m-1}^{\prime}\right)-\alpha_{m-1} \xi^{\prime}\left(\psi_{m-1}^{\prime}\right)\right]\right.$

$\underline{E_{l} * *}=E\left(\psi_{m-1}\right) \sin \psi_{m-1}^{\prime}-E^{\prime}\left(\psi_{m-1}^{\prime}\right) \cdot \sin \psi_{m-1}$

つぎに,

$N_{m j}=\frac{W_{j}}{R_{0 j}}\left\{\left[\mathfrak{\Omega}_{2 j} B_{n 2} * *+\mathfrak{\Omega}_{3 j} B_{n 3} * *\right] \frac{R_{j}{ }^{2}}{E_{s} C_{w j}}+\left[\mathfrak{\Omega}_{2 j} C_{n 2} * *+\Omega_{3 j} C_{n 3} * *\right] \frac{1}{G_{s} J}+\left[\mathfrak{\Omega}_{2 j} D_{n 2} * *+\Omega_{3 j} D_{n 3} * *\right] \frac{Z_{j}}{G_{s} C_{w j}{ }^{2}}\right\}$

\section{(i) $j=m$ に対して,}

$B_{n 2} * *=\frac{1}{\alpha_{m}^{2}+1}\left\{\alpha_{m}\left[\mathfrak{B}^{\prime}\left(\psi_{m}\right) \cdot \sinh \alpha_{m} \psi_{m}^{\prime}+\mathfrak{B}\left(\psi_{m}^{\prime}\right) \cdot \sinh \alpha_{m} \psi_{m}\right]+\mathfrak{X}^{\prime}\left(\psi_{m}\right) \sin \psi_{m}^{\prime}+\mathfrak{A}\left(\psi_{m}^{\prime}\right) \cdot \sin \psi_{m}\right\}$

$B_{n 3} * *=\frac{-1}{\alpha_{m}}\left\{\mathfrak{B}^{\prime}\left(\psi_{m}\right) \sinh \alpha_{m} \psi_{m}^{\prime}+\mathfrak{B}\left(\psi_{m}^{\prime}\right) \cdot \sinh \alpha_{m} \psi_{m}\right\}$

$C_{n 2} * *=\frac{\alpha_{m}^{3}}{\alpha_{m}^{2}+1}\left\{\xi\left(\psi_{m}^{\prime}\right) \sinh \alpha_{m} \psi_{m}-\xi^{\prime}\left(\psi_{m}\right) \cdot \sinh \alpha_{m} \psi_{m}^{\prime}+\mathfrak{D}^{\prime \prime}\left(\psi_{m}\right) \cdot \sin \psi_{m}^{\prime}-\mathfrak{D}\left(\psi_{m}{ }^{\prime}\right) \sin \psi_{m}\right\}$

$C_{n 3} * *=\alpha_{m}\left\{\xi^{\prime}\left(\psi_{m}\right) \cdot \sinh \alpha_{m} \psi_{m}^{\prime}-\xi\left(\psi_{m}{ }^{\prime}\right) \cdot \sinh \alpha_{m} \psi_{m}\right\}+\frac{\sinh \alpha_{m} \psi_{m}^{\prime}}{\sinh \alpha_{m} \Phi_{m}}-\frac{\psi_{m}{ }^{\prime}}{\Phi_{m}}$

$\underline{D_{n 2} * *}=\frac{\alpha_{m}}{\alpha_{m}^{2}+1}\left\{\alpha_{m}^{2}\left[\xi\left(\psi_{m}^{\prime}\right) \cdot \sinh \alpha_{m} \psi_{m}-\xi^{\prime}\left(\psi_{m}\right) \cdot \sinh \alpha_{m} \psi_{m^{\prime}}\right]+\mathscr{D}\left(\psi_{m}^{\prime}\right) \cdot \sin \psi_{m}-\mathfrak{D}^{\prime}\left(\psi_{m}\right) \sin \psi_{m}{ }^{\prime}\right\}$

$\underline{D_{n 3} * *}=\alpha_{m}\left\{\xi^{\prime}\left(\psi_{m}\right) \cdot \sinh \alpha_{m} \psi_{m}{ }^{\prime}-\xi\left(\psi_{m}{ }^{\prime}\right) \cdot \sinh \alpha_{m} \psi_{m}\right\}$

(ii) $j=m-1$ 亿対して,

$B_{n 2} * *=\frac{1}{\alpha_{m-1}{ }^{2}+1}\left\{\alpha_{m-1}\left[\mathfrak{B}\left(\psi_{m-1}\right) \cdot \sinh \alpha_{m-1} \psi_{m-1}{ }^{\prime}+\mathfrak{B}^{\prime}\left(\psi_{m-1}{ }^{\prime}\right) \cdot \sinh \alpha_{m-1} \psi_{m-1}\right]+\mathfrak{X}\left(\psi_{m-1}\right) \cdot \sin \psi_{m-1}{ }^{\prime}\right.$

$\left.+\mathfrak{U}^{\prime}\left(\psi_{m-1}{ }^{\prime}\right) \cdot \sin \psi_{m-1}\right\}$

$B_{n_{3}} * *=\frac{-1}{\alpha_{m-1}}\left\{\mathfrak{B}\left(\psi_{m-1}\right) \cdot \sinh \alpha_{m-1} \psi_{m-1}{ }^{\prime}+\mathfrak{B}^{\prime}\left(\psi_{m-1}{ }^{\prime}\right) \sinh \alpha_{m-1} \psi_{m-1}\right\}$

$C_{n 2} * *=\frac{\alpha_{m-1}{ }^{3}}{\alpha_{m-1}{ }^{2}+1}\left\{\xi\left(\psi_{m-1}\right) \cdot \sinh \alpha_{m-1} \psi_{m-1}{ }^{\prime}-\xi^{\prime}\left(\psi_{m-1}{ }^{\prime}\right) \sinh \alpha_{m-1} \psi_{m-1}+D^{\prime \prime}\left(\psi_{m-1}^{\prime}\right) \cdot \sin \psi_{m-1}\right.$

$\left.-\mathfrak{D}\left(\psi_{m-1}\right) \cdot \sin \psi_{m-1}{ }^{\prime}\right\}$

$C_{n 3} * *=\alpha_{m-1}\left\{\xi^{\prime}\left(\psi_{m-1}^{\prime}\right) \cdot \sinh \alpha_{m-1} \psi_{m-1}-\xi\left(\psi_{m-1}\right) \sinh \alpha_{m-1} \psi_{m-1}{ }^{\prime}\right\}+\frac{\sinh \alpha_{m-1} \psi_{m-1}}{\sinh \alpha_{m-1} \Phi_{m-1}}-\frac{\psi_{m-1}}{\Phi_{m-1}}$

$\underline{D_{n 2} * *}=\frac{\alpha_{m-1}}{\alpha_{m-1}{ }^{2}+1}\left\{\alpha_{m-1}^{2}\left[\xi\left(\psi_{m-1}\right) \cdot \sinh \alpha_{m-1} \psi_{m-1}{ }^{\prime}-\xi^{\prime}\left(\psi_{m-1}^{\prime}\right) \cdot \sinh \alpha_{m-1} \psi_{m-1}\right]\right.$

$$
\left.+\mathfrak{D}\left(\psi_{m-1}\right) \cdot \sin \psi_{m-1}{ }^{\prime}-\mathfrak{D}^{\prime \prime}\left(\psi_{m-1}{ }^{\prime}\right) \cdot \sin \psi_{m-1}\right\}
$$

$\underline{D}_{n} * *=\alpha_{m-1}\left\{\xi^{\prime}\left(\psi_{m-1}{ }^{\prime}\right) \cdot \sinh \alpha_{m-1} \psi_{m-1}-\xi\left(\psi_{m-1}\right) \cdot \sinh \alpha_{m-1} \psi_{m-1}{ }^{\prime}\right\}$

式 (68)〜(95) にふくまれる係数 $\mathfrak{X}^{\prime \prime}$ と $\mathfrak{D}^{\prime \prime}$ は次式で与えられる。

$$
\begin{aligned}
& \mathfrak{A}^{\prime \prime}\left(\varphi_{j}\right)=\frac{\alpha_{j} \cosh \alpha_{j} \varphi_{j} \sin \varphi_{j}{ }^{\prime}+\sinh \alpha_{j} \varphi_{j} \cos \varphi_{j}{ }^{\prime}-\alpha_{j} \sin \Phi_{j}}{\left(\alpha_{j}{ }^{2}+1\right) \sin \Phi_{j} \sinh \alpha_{j} \Phi_{j}} \\
& \mathfrak{D}^{\prime \prime}\left(\varphi_{j}\right)=\frac{\cosh \alpha_{j} \varphi_{j} \sin \varphi_{j}-\alpha_{j} \sinh \alpha_{j} \varphi_{j}{ }^{\prime} \cos \varphi_{j}+\alpha_{j} \sinh \alpha_{j} \Phi_{j}}{\left(\alpha_{j}{ }^{2}+1\right) \sin \Phi_{j} \sinh \alpha_{j} \Phi_{j}}
\end{aligned}
$$




\section{（4）藮中荷重}

第 $j$ スパン内の断面 $\varphi_{j}=\psi_{j}$ 上, 曲率中心 $O$ 上り半 径 $\bar{R}_{j}$ の点潗中荷重 $P_{j}$ が作用する場合には, $W_{j} \rightarrow$ $R_{0 j} P_{j}, \mathbb{\Omega}_{2 j} \rightarrow \bar{R}_{j}, \Omega_{3 j} \rightarrow R_{0 j}$ と置きかえ机，（3）項の 各式がそのまま適用できる。

以上のような荷重が, 第 $m$ スパンおよび第 $m-1$ ス パンに同時に載荷した場合には, 荷重項 $L_{m}$ および $N_{m}$ はつぎのようである。

$$
L_{m}=L_{m m}+L_{m, m-1}, N_{m}=N_{m m}+N_{m, m-1}
$$

\section{6. 直線桁と曲線桁とが連続する場合}

直線桁と曲線桁とが中間支点上で連続するような連続 桁橋に関しては, 曲線桁の部分は 4. 5.に示す公式によ って, 弾性方程式の, そのスパンに関方係数および荷 重項を計算できる。直線行部分のスパンに関してはつぎ の公式を用いればよい。

\section{(1) 弾性方程式の係数}

a) 第 $m$ スパンが直線の場合

$$
\begin{aligned}
& a_{m m}=\frac{l_{m}}{3 E_{s} I_{y m^{\prime}}}+\frac{1}{G_{s} F_{w m} l_{m}}+[a]_{m, m-1} \\
& a_{m, m+1}=\frac{l_{m}}{6 E_{s} I_{y m^{\prime}}}-\frac{1}{G_{s} F_{w m} l_{m}}
\end{aligned}
$$

ここに $F_{w}$ は腹板総断面積

$$
\begin{aligned}
& b_{m m}=[b]_{m, m-1} \quad b_{m, m+1}=0 \\
& d_{m m}=\frac{\overline{\mathfrak{B}}\left(l_{m}\right)}{E_{s} C_{w m}}+\frac{\overline{\mathcal{K}}\left(l_{m}\right)}{G_{s} J_{m}}+\alpha_{m}{ }^{2} \bar{\xi}\left(l_{m}\right) \frac{Z_{m}}{G_{s} C_{w m}{ }^{2}} \\
& +[d]_{m, m-1} \\
& d_{m, m+1}=\frac{\overline{\mathfrak{B}^{\prime}}\left(l_{m}\right)}{E_{s} C_{w m}}+\frac{\bar{K}^{\prime}\left(l_{m}\right)}{G_{s} J_{m}}-\alpha_{m}^{2 \overline{\boldsymbol{\xi}}^{\prime}\left(l_{m}\right) \frac{Z_{m}}{G_{s} C_{w m^{2}}}}
\end{aligned}
$$

ここにしは支間長である。また，

$$
\begin{aligned}
& \overline{\mathfrak{B}}\left(x_{m}\right)=\frac{\sinh 2 \alpha_{m} x_{m}-2 \alpha_{m} x_{m}}{4 \alpha_{m} \sinh \mathrm{h}^{2} \alpha_{m} l_{m}} \\
& \bar{K}\left(x_{m}\right)=\alpha_{m}{ }^{2} \bar{\xi}\left(x_{m}\right)-\frac{1}{l_{m}} \\
& \bar{\xi}\left(x_{m}\right)=\frac{\sinh 2 \alpha_{m} x_{m}+2 \alpha_{m} x_{m}}{4 \alpha_{m} \operatorname{sin~h}{ }^{2} \alpha_{m} l_{m}} \\
& \overline{\mathfrak{B}}^{\prime}\left(x_{m}\right)=\frac{\sinh ^{2} \alpha_{m} x_{m}}{2 \alpha_{m} \sinh \alpha_{m} l_{m}}-\overline{\mathfrak{B}}\left(x_{m}\right) \cdot \cosh \alpha_{m} l_{m} \\
& \bar{K}^{\prime}\left(x_{m}\right)=-\alpha_{m}^{2} \cdot \bar{\zeta}^{\prime}\left(x_{m}\right)+\frac{1}{l_{m}} \\
& \bar{\xi}^{\prime}\left(x_{m}\right)=\bar{\xi}\left(x_{m}\right) \cosh \alpha_{m} l_{m}-\frac{\sinh ^{2} \alpha_{m} x_{m}}{2 \alpha_{m} \sinh \alpha_{m} l_{m}}
\end{aligned}
$$

b) 第 $m-1$ スパンが直線枌の場合

$$
\begin{aligned}
& a_{m m}=\frac{l_{m-1}}{3 E_{s} I_{y, m-1}{ }^{\prime}}+\frac{1}{\underline{G_{s} F_{w, m-1} l} l_{m-1}}+[a]_{m m} \\
& a_{m, m-1}=\frac{l_{m-1}}{6 E_{s} I_{y, m-1}{ }^{\prime}}-\frac{1}{G_{s} F_{w, m-1} l_{m-1}} \\
& b_{m m}=[b]_{m m}, \quad b_{m, m-1}=0
\end{aligned}
$$

$$
\begin{aligned}
d_{m m}= & \frac{\overline{\mathcal{v}}\left(l_{m-1}\right)}{E_{s} C_{w, m-1}}+\frac{\bar{K}\left(l_{m-1}\right)}{G_{s} J_{m-1}} \\
& +\frac{\alpha_{m-1}{ }^{2} \bar{\xi}\left(l_{m-1}\right) \frac{Z_{m-1}}{G_{s} C_{w, m-1}{ }^{2}}}{d_{m, m-1}=}=\frac{\bar{W}^{\prime}\left(l_{m-1}\right)}{E_{s} C_{w, m-1}}+\frac{\bar{K}^{\prime}\left(l_{m-1}\right)}{G_{s} J_{m-1}} \\
& -\alpha_{m-1}{ }^{2} \bar{\xi}^{\prime}\left(l_{m-1}\right) \frac{Z_{m-1}}{G_{s} C_{w, m-1}{ }^{2}} \cdots \cdots . . .
\end{aligned}
$$

\section{（1）弾性方程式の荷重項}

a) 等分布荷重 横断面方向に幅 $a_{j}$ を有する荷重強 度 $p_{j}$ なる等分布荷重が, 第 $j$ スパンに載荷する場合 について荷重項 $L_{m j}, N_{m j}$ をつぎの式で求めうる。 $e_{j}$ は荷重の重心とせん断中心との距離である。

$$
\begin{aligned}
& L_{m j}=\frac{p_{j} a_{j} l_{j}{ }^{3}}{24 E_{s} I_{y j^{\prime}}} \\
& N_{m j}=p_{j} e_{j} a_{j}\left(\frac{\bar{C}_{n}{ }^{*}}{G_{s} J_{j}}+\bar{D}_{n} * \frac{Z_{j}}{G_{s} C_{w j^{2}}}\right)
\end{aligned}
$$

こてに，第 $m$ スパンが直線の場合は， $j=m$

第 $m-1$ スパンが直線の場合は, $j=m-1$ と する。

$$
\begin{aligned}
& \bar{C}_{n}{ }^{*}=\overline{\mathfrak{B}}\left(l_{j}\right)+\overline{\mathfrak{B}}^{\prime}\left(l_{j}\right)+\overline{\boldsymbol{\xi}}\left(l_{j}\right)-\overline{\boldsymbol{\xi}}^{\prime}\left(l_{j}\right)-\frac{l_{j}}{2} \\
& {\overline{D_{n}}}_{n}=\overline{\boldsymbol{\xi}}\left(l_{j}\right)-\bar{\xi}^{\prime}\left(l_{j}\right) \ldots \ldots \ldots \ldots \ldots \ldots \ldots \ldots \ldots \ldots \ldots \ldots \ldots \ldots \ldots \ldots
\end{aligned}
$$

b) 軸方向線荷重 荷重強度 $W_{j}$ なる線荷重が偏心 距離 $\boldsymbol{e}_{j}$ で載荷する場台には， $L_{m j}$ および $N_{m j}$ は公式 (113) および (114) において, $p_{j} a_{j} \rightarrow W_{j}$ と置きかえ ればそのまま準用できる。

c) 横方向線荷重 横断面方向に幅 $a$ を有する荷重強 度 $W$ なる線荷重が， $x=c$ 亿偏心距離 $e$ で作用する場 合について考える。

(1) 第 $m$ スパンが直線析の場合：第 $m$ スパンが直 線桁で同じスパンに上記の線荷重が載荷すれば荷重項は つぎのようになる。

$$
\begin{aligned}
& L_{m m}=\frac{W_{m} a_{m} c_{m}}{6 E_{s} \bar{I}_{y m} l_{m}^{-}}\left(2 l_{m}-c_{m}\right)\left(l_{m}-c_{m}\right) \cdots \cdots(117) \\
& N_{m m}=W_{m} e_{m} a_{m}\left(\frac{\bar{B}_{n}{ }^{* *}}{E_{s} C_{w m}}+\frac{\bar{C}_{n}{ }^{* *}}{G_{s} J_{m}}+\frac{\bar{D}_{n}{ }^{* *} Z_{m}}{\underline{G_{s} C_{w m}{ }^{2}}}\right)
\end{aligned}
$$

そして $l_{m}-c_{m}=c_{m}{ }^{\prime}$ と置けば，各項の係数は，つぎ のようである。

$$
\begin{aligned}
& \bar{B}_{n} * *=\frac{-1}{\alpha_{m}}\left[\overline{\mathfrak{S}^{\prime}}\left(c_{m}\right) \cdot \sinh \alpha_{m} c_{m}{ }^{\prime}\right. \\
& \left.+\overline{\mathfrak{B}}\left(c_{m}{ }^{\prime}\right) \sinh \alpha_{m} c_{m}\right] \\
& \overline{\boldsymbol{C}}_{n}{ }^{* *}=\alpha_{m}\left[\bar{\xi}^{\prime}\left(c_{m}\right) \cdot \sinh \alpha_{m} c_{m}{ }^{\prime}\right. \\
& \left.-\overline{\boldsymbol{\xi}}\left(c_{m}{ }^{\prime}\right) \cdot \sinh \alpha_{m} c_{m}\right]+\frac{\sinh \alpha_{m} c_{m}{ }^{\prime}}{\sinh \alpha_{m} l_{m}}-\frac{c_{m}{ }^{\prime}}{l_{m}} \\
& \text { ………...(120) } \\
& \bar{D}_{n} * *=\alpha_{m}\left[\bar{\xi}^{\prime}\left(c_{m}\right) \cdot \sinh \alpha_{m} c_{m}^{\prime}\right. \\
& \left.-\bar{\xi}\left(c_{m}{ }^{\prime}\right) \cdot \sinh \alpha_{m} c_{m}\right]
\end{aligned}
$$

(2) 第 $m-1$ スパンが直線析の場合 : 


$$
\begin{aligned}
& L_{m, m-1}=\frac{W_{m-1} a_{m-1} c_{m-1}}{6 E_{s} I_{y, m-1}{ }^{\prime} l_{m-1}}\left(l_{m-1}{ }^{2}-c_{m-1}{ }^{2}\right) \\
& N_{m, m-1}=W_{m-1} e_{m-1} a_{m-1}\left(\frac{\bar{B}_{n} * *}{E_{s} G_{w, m-1}}+\frac{\bar{C}_{n} * *}{G_{s} J_{m-1}}\right. \\
& \left.+\frac{\bar{D}_{n} * * Z_{m-1}}{\underline{G_{s} C_{w, m-1}}}\right)
\end{aligned}
$$

ここに,

$$
\begin{aligned}
\bar{B}_{n} * *= & \frac{-1}{\alpha_{m-1}}\left[\overline{\mathfrak{B}}\left(c_{m-1}\right) \cdot \sinh \alpha_{m-1} c_{m-1}{ }^{\prime}\right. \\
& \left.+\overline{\mathfrak{B}}^{\prime}\left(c_{m-1}\right) \sinh \alpha_{m-1} c_{m-1}\right] \cdots \cdots \cdots \cdots(124) \\
\bar{C}_{n} * *= & \alpha_{m-1}\left[\bar{\xi}^{\prime}\left(c_{m-1}{ }^{\prime}\right) \cdot \sinh \alpha_{m-1} c_{m-1}-\bar{\xi}\left(c_{m-1}\right) \cdot\right. \\
& \left.\sinh \alpha_{m-1} c_{m-1}{ }^{\prime}\right]+\frac{\sinh \alpha_{m-1} c_{m-1}}{\sinh \alpha_{m-1} l_{m-1}}-\frac{c_{m-1}}{l_{m-1}}
\end{aligned}
$$
(125)

$$
\begin{aligned}
\underline{\bar{D}}_{n}^{* *}= & \alpha_{m-1}\left[\bar{\xi}^{\prime}\left(c_{m-1}{ }^{\prime}\right) \cdot \sinh \alpha_{m-1} c_{m-1}\right. \\
& \left.-\bar{\xi}\left(c_{m-1}\right) \cdot \sinh \alpha_{m-1} c_{m-1}{ }^{\prime}\right] \ldots \ldots
\end{aligned}
$$

d) 集中荷重 第 $j$ スパンが直線桁で同じスパンに集 中荷重 $P_{j}$ が載荷する場合には，c）の結果において $W_{j} a_{j} \rightarrow P_{j}$ と置きかえ, $j=m$ あるいは $j=m-1$ とし て式 (117)～(121) あるいは式 (122)～(126) をそのま ま準用すればよい。

\section{7. 連続曲線桁橋の変形量}

連続曲線桁橋のたわみおよび断面回転角は，いずれも そのスパンを単純桁とした場合の值と支点モーメントに よる值との和として与えられる。

\section{(1) 断面回転角 $\boldsymbol{\beta}_{m}$}

$$
\begin{aligned}
& \beta_{m}=\beta_{m 0}+\frac{R_{m}{ }^{2}}{E_{s} C_{w m}\left(\alpha_{m}{ }^{2}+1\right)}\left\{\left(\mathfrak{M}{ }_{m}-\frac{R_{m}}{\alpha_{m}{ }^{2}+1} M_{m}\right)\left(\frac{\sinh \alpha_{m} \varphi_{m}{ }^{\prime}}{\sinh \alpha_{m} \Phi_{m}}-\frac{\sin \varphi_{m}{ }^{\prime}}{\sin \Phi_{m}}\right)\right. \\
& \left.+\left(\mathfrak{M}_{m+1}-\frac{R_{m}}{\alpha_{m}{ }^{2}+1} M_{m+1}\right)\left(\frac{\sinh \alpha_{m} \varphi_{m}}{\sinh \alpha_{m} \Phi_{m}}-\frac{\sin \varphi_{m}}{\sin \Phi_{m}}\right)\right\}+\frac{\lambda_{m}}{R_{m} \sin \Phi_{m}}\left\{M _ { m } \left(\varphi_{m} \cos \varphi_{m}^{\prime}\right.\right. \\
& \left.\left.-\Phi_{m} \frac{\sin \varphi_{m}}{\sin \Phi_{m}}\right)+M_{m+1}\left(\Phi_{m} \cos \Phi_{m} \frac{\sin \varphi_{m}}{\sin \Phi_{m}}-\varphi_{m} \cos \varphi_{m}\right)\right\}
\end{aligned}
$$

ことに,

$$
\lambda=\frac{R^{2}}{2}\left[\frac{R^{2}}{E_{s} C_{w}\left(\alpha^{2}+1\right)}+\frac{1}{E_{s} I_{y}{ }^{\prime}}\right]
$$

\section{(2) たわみ $\delta_{m}$}

せん断中心のたわみ $\delta_{m}$ は次式で与えられる。

$$
\begin{aligned}
& \delta_{m}=\delta_{m 0}+R_{0 m}\left\{\frac{M_{m}}{G_{s} J_{m}}\left[\frac{1}{\alpha_{m}^{2}+1}\left(\frac{\sinh \alpha_{m} \varphi_{m}^{\prime}}{\sinh \alpha_{m} \Phi_{m}}+\alpha_{m}{ }^{2} \frac{\sin \varphi_{m}^{\prime}}{\sin \Phi_{m}}\right)-\frac{\varphi_{m}^{\prime}}{\Phi_{m}}\right]+\frac{\mathfrak{M}_{m+1}}{G_{s} J_{m}}\left[\frac { 1 } { \alpha _ { m } { } ^ { 2 } + 1 } \left(\frac{\sinh \alpha_{m} \varphi_{m}}{\sinh \alpha_{m} \Phi_{m}}\right.\right.\right. \\
& \left.\left.+\alpha_{m}{ }^{2} \frac{\sin \varphi_{m}}{\sin \Phi_{m}}\right)-\frac{\varphi_{m}}{\Phi_{m}}\right]-M_{m}\left\{\left[\frac{R_{m}}{G_{s} J_{m}\left(\alpha_{m}{ }^{2}+1\right)^{2}}\left(\frac{\sinh \alpha_{m} \varphi_{m}^{\prime}}{\sinh \alpha_{m} \Phi_{m}}+\alpha_{m}^{2}+2 \alpha_{m}{ }^{2} \frac{\sin \varphi_{m}^{\prime}}{\sin \Phi_{m}}\right)\right.\right. \\
& \left.\left.+\frac{R_{m}}{G_{s} J_{m}} \frac{\varphi_{m}^{\prime}}{\Phi_{m}}\right]+\frac{\lambda_{m}}{R_{m} \sin \Phi_{m}}\left(\varphi_{m} \cos \varphi_{m}^{\prime}-\Phi_{m} \frac{\sin \varphi_{m}}{\sin \Phi_{m}}\right)\right\}-M_{m+1}\left\{\left[\frac { R _ { m } } { G _ { s } J _ { m } ( \alpha _ { m } ^ { 2 } + 1 ) ^ { 2 } } \left(\frac{\sinh \alpha_{m} \varphi_{m}}{\sinh \alpha_{m} \Phi_{m}}\right.\right.\right. \\
& \left.\left.\left.\left.+\overparen{\alpha_{m}^{2}+2} \alpha_{m}^{2} \frac{\sin \varphi_{m}}{\sin \Phi_{m}}\right)+\frac{R_{m}}{G_{s} J_{m}} \frac{\varphi_{m}}{\Phi_{m}}\right]+\frac{\lambda_{m}}{R_{m} \sin \Phi_{m}}\left(\Phi_{m} \cos \Phi_{m} \frac{\sin \varphi_{m}}{\sin \Phi_{m}}-\varphi_{m} \cos \varphi_{m}\right)\right\}\right\}
\end{aligned}
$$

したがって橋断面内でせん断中心より外側, 半径方向 に $Y$ なる水平距離にある点のたわみ $\delta_{m}(Y)$ は, 次式 で与えられる。

$$
\delta_{m}(Y)=\delta_{m}-Y \beta_{m}
$$

\section{8. 数值計算例}

図一2 に示すように 3 スパン連続合成箱桁橋につい て, 断面力の影響線を求めてみる。3つのスパンはいず れも, $33.527 \mathrm{~m}$ の等スパンで, 両側スパンは直線桁か らなり中央スパンは曲率半径 $30 \mathrm{~m}$ の円弧状の曲線桁か らなるものとする。また有効幅員は $6.705 \mathrm{~m}$ で, 全橋 長にわたって等断面とする。横断面の形状および主要寸 法は文献 4) の数值計算例のものと同じである。

移動する単位集中荷重について, 弾性方程式を組立て た。まず，断面諸量は敩密には直線支間と曲線支間で相 違し,つぎのようである。

$C_{w_{1}}=C_{w_{3}}=0.48803 \times 10^{12} \mathrm{~cm}^{6}$

\section{図一2 連続曲線桁橋}

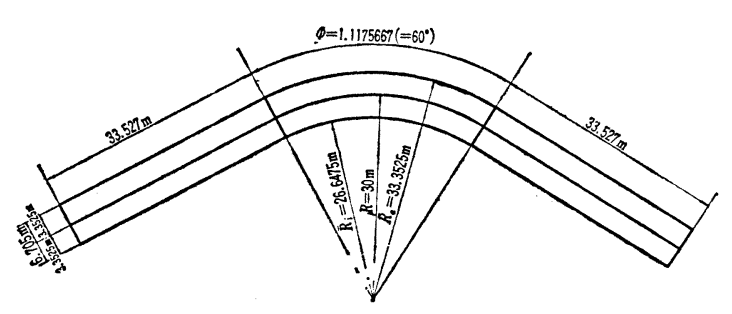

$C_{w_{2}}=0.48135 \times 10^{12} \mathrm{~cm}^{6} \quad I_{y_{1}}=I_{y_{3}}=10.2308 \times 10^{6} \mathrm{~cm}^{4}$ $I_{y_{2}}=10.2601 \times 10^{6} \mathrm{~cm}^{4} \quad J_{1}=J_{3}=4.9773 \times 10^{6} \mathrm{~cm}^{4}$ $J_{2}=5.0229 \times 10^{6} \mathrm{~cm}^{4} \quad \alpha_{1}=\alpha_{3}=1.972 \times 10^{-3} 1 / \mathrm{cm}$ $\alpha_{2}=5.9364$

諸係数の数值は, 
$\mathfrak{A}\left(\Phi_{2}\right)=0.150365, \mathfrak{B}\left(\Phi_{2}\right)=0.0822389$, $\mathfrak{D}\left(\Phi_{2}\right)=0.107373, \quad \xi\left(\Phi_{2}\right)=0.0822466$, $\overline{\mathfrak{B}}\left(l_{1}\right)=248.130, \quad \bar{K}\left(l_{1}\right)=0.666751 \times 10^{-3}$, $\overline{\boldsymbol{\xi}}\left(l_{1}\right)=248.154, \quad K\left(\Phi_{2}\right)=2.00365$, $\mathfrak{A}^{\prime}\left(\Phi_{2}\right)=0.0302612, \quad \mathfrak{B}^{\prime}\left(\Phi_{2}\right)=1.24758 \times 10^{-3}$, $\mathscr{D}^{\prime}\left(\Phi_{2}\right)=0.182272, \quad \xi^{\prime}\left(\Phi_{2}\right)=1.69043 \times 10^{-3}$, $K^{\prime}\left(\Phi_{2}\right)=0.835229$ $A\left(\Phi_{2}\right)=0.447812, \quad B\left(\Phi_{2}\right)=0.174600 \times 10^{-3}$, $C\left(\Phi_{2}\right)=0.0255884, D\left(\Phi_{2}\right)=1.94798 \times 10^{-3}$,
1.424510
0.561727
$0.637130 \times 10^{-3}$
0.561727
1.424510
$0.471472 \times 10^{-3}$
$0.637130 \times 10^{-3}$
$0.471472 \times 10^{-3}$
$8.923880 \times 10^{-6}$
$0.471472 \times 10^{-3}$
$0.637130 \times 10^{-3}$
$0.7331305 \times 10^{-6}$

荷重項は，(1)第 1 スパン載荷 $\quad L_{2}=L_{21}, L_{3}=0, L_{3}$ $=0, N_{2}=N_{21}, N_{3}=0$, (2) 第 2 スパン載荷 $L_{2}=L_{22}$, $L_{3}=L_{32}, N_{2}=N_{22}, N_{3}=N_{32}$, (3) 第3 スパン載荷 $L_{2}$ $=0, L_{3}=L_{33}, N_{2}=0, N_{3}=N_{33}$,

\section{(1) 断面力の影䈏線}

弾性方程式 (131) の解から，中間支点 Bにおける曲げ モーメント $M_{2}$ と曲げねじりモーメント $\mathfrak{B}_{2}$ に関する影 響線を描けば，図一-3,4 のようになる。以下図において 実線は有効幅員の外縁, 点線は内縁, 鎖線は中央にそ。 て単位集中荷重を移動した場合を示す。

支点曲げモーメントに関しては中央スパンの曲線部分 において，外析側載荷でかなり大きい縦距を有する。ま た内枌側載荷では比較的小さい。すなわち外析側載荷は 内析側載荷の約 2 倍の大きさとなる。ととろが両側スパ

\section{図一3 支点 B の曲げモーメント影響線}
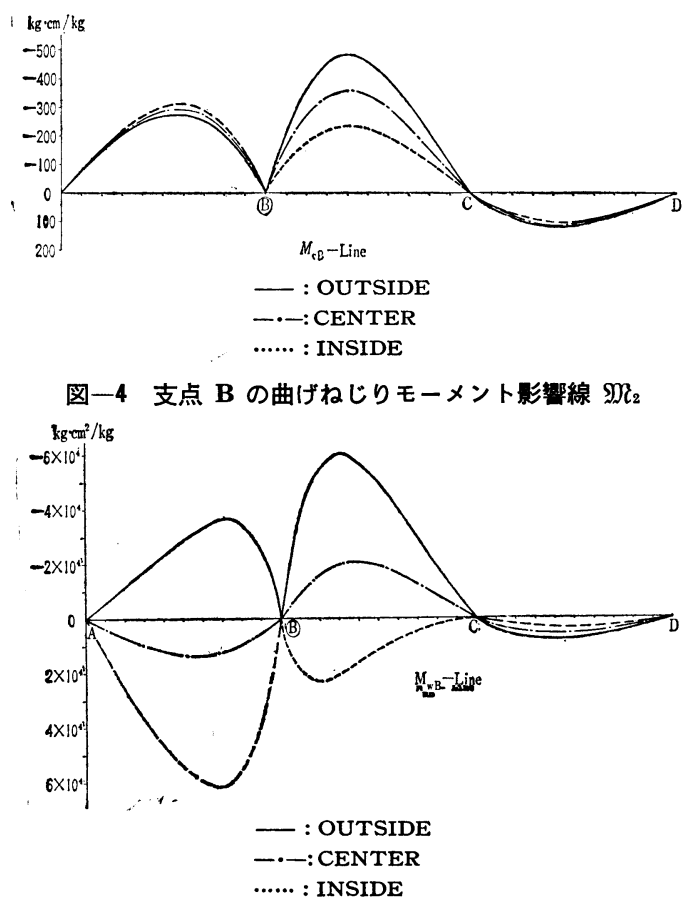

$E\left(\Phi_{2}\right)=0.934857, \quad F\left(\Phi_{2}\right)=1.87982 \times 10^{-3}$, $G\left(\Phi_{2}\right)=0.195003, \quad H\left(\Phi_{2}\right)=-0.0623891$, $A^{\prime}\left(\Phi_{2}\right)=0.253435, \quad B^{\prime}\left(\Phi_{2}\right)=0.147829 \times 10^{-3}$, $C^{\prime}\left(\Phi_{2}\right)=0.0245678, \quad D^{\prime}\left(\Phi_{2}\right)=0.948405 \times 10^{-3}$, $E^{\prime}\left(\Phi_{2}\right)=0.858866, \quad F^{\prime}\left(\Phi_{2}\right)=0.800575 \times 10^{-3}$, $G^{\prime}\left(\Phi_{2}\right)=0.159026, \quad H^{\prime}\left(\Phi_{2}\right)=-0.0282130$,

てれより, 弾性方程式を行列表示すれば, 式 (131) の ようである。

$\left.\begin{array}{c}0.471472 \times 10^{-3} \\ 0.637130 \times 10^{-3} \\ 0.7331305 \times 10^{-6} \\ 8.923880 \times 10^{-6}\end{array}\right]\left[\begin{array}{c}M_{2} \\ M_{3} \\ \mathfrak{M}_{2} \\ \mathfrak{M}_{3}\end{array}\right]=\left[\begin{array}{c}L_{2} \\ L_{3} \\ N_{2} \\ N_{3}\end{array}\right]$

ンの直線部分においては, 荷重の偏心は橋断面曲げモ一 メントにあまり影響しないととがわかる。

支点曲げねじりモーメントの影響線については, 支点 $\mathrm{B}$ をはさむ側スパン $\mathrm{AB}$ と中央スパン $\mathrm{BC}$ において は，外桁側載荷と内桁側とで符号が逆になっている。乙 れは外力トルクが逆方向に作用すれば曲げねじりモーメ ントも反対符号になるととを示している。

つぎに，図一5に中央スパンの中央断面における曲げ モーメント $M_{y}$ の影響線を示す。全橋長にわたって載 荷位置の偏心亿よる縦距の変化量はあまりない。内桁側 載荷の方が外析側載荷よりわずかに絶対值が大きい程度 である。全般的にみて, 橋軸方向の変化状態は直線連続 桁の曲げモーメント影響線と類似した形状をしている。

图一6に中央スパンの中央断面における曲げねじりモ ーメント $M_{w}$ の影響線を示す。中央スパンにおいては

图一5 第 2 支間 $l_{2} / 2$ 断面の曲げモーメント影锌線 $M_{y}$

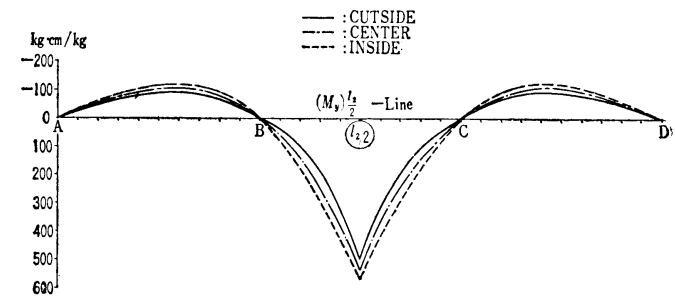

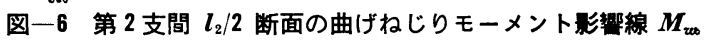

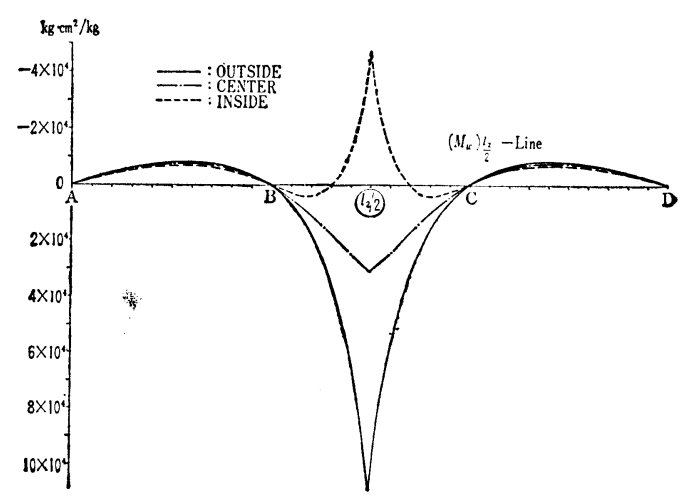


外析側載荷と内枌側載荷とで符号が逆となる。絶体值は 外析側が内桁側の 2 倍をとしている。両側スパンでは偏 心の影響がなく，総体に絶対值は非常に小さい。との $M_{w}$ による垂直応力 $\sigma_{w}$ を曲げモーメント $M_{y}$ による 曲げ垂直応力 $\sigma_{b}$ に加算すれば, 載荷側桁に生ずる合垂 直応力 $\sigma$ は非載荷側桁に生ずるものよりも大きくなる。 その程度は外桁側載荷の場合の方がいちじるしい。橋軸 上に載荷する場合といえども，中央スパンについてみる に, 正の曲げねじりモーメントによる $\sigma_{w}$ が $\sigma_{b}$ に加算 されるととになるので, 外桁の垂直応力が内析のそれよ り大きい。これは曲線桁部分の橋軸線上に載荷しても外 方にねじられるように変形し，外栴と内桁とに応力の差 が現われることを示す。それで $\sigma_{w}$ が $\sigma_{b}$ に比して十分 小さい閉断面をもつ曲線橋では, 内, 外の主枌の垂直応 力の差異があまり生じないので有利である。

図一1には中央スパンの中央断面における St. Venant ねじりモーメント $T_{s}$ の影響線を示す。それは中央断面 の両側で逆対称形状となっている。やはり外桁側載荷の 方が縦距の絶対值が大きい。また側スパン載荷に対して も，かなりの大きさの $T_{s}$ が生ずることは注目すべきで ある。

図一8には中央スパンの中央断面における 2 次ねじり モーメント $T_{w}$ の影響線を示す。これは中央断面にお

図一7 第 2 支間 $l_{2} / 2$ 断面の St. Venant ねじりモーメント $T$, 影譬線

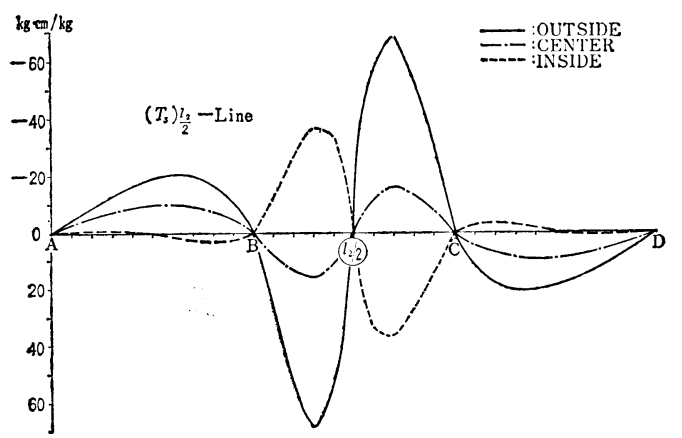

図一8 第 2 支間 $l_{2} / 2$ 断面 2 次ねじりモーメント $T_{w v}$ inf line $T_{w}$

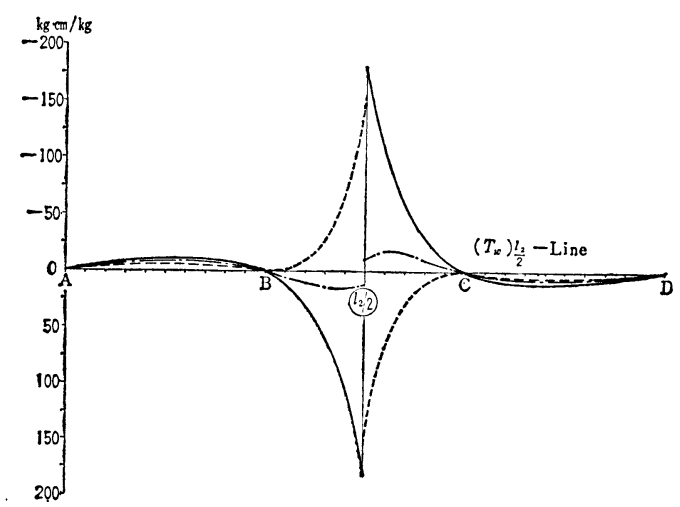

いて不連続で，その両側で逆対称である。そして中央断 面を離れると急に減衰する。したがって側スパンの荷重 の影響はほとんどないととを知る。

図一9，10 はそれぞれ中央スパンにおける支点 B上断 面および中央断面におけるせん断力Qの影響線である。

いずれにも霨心および曲率の影響がほとんど喼められ ない。そして面線連続析のせん断力影響線と全く似てい る。
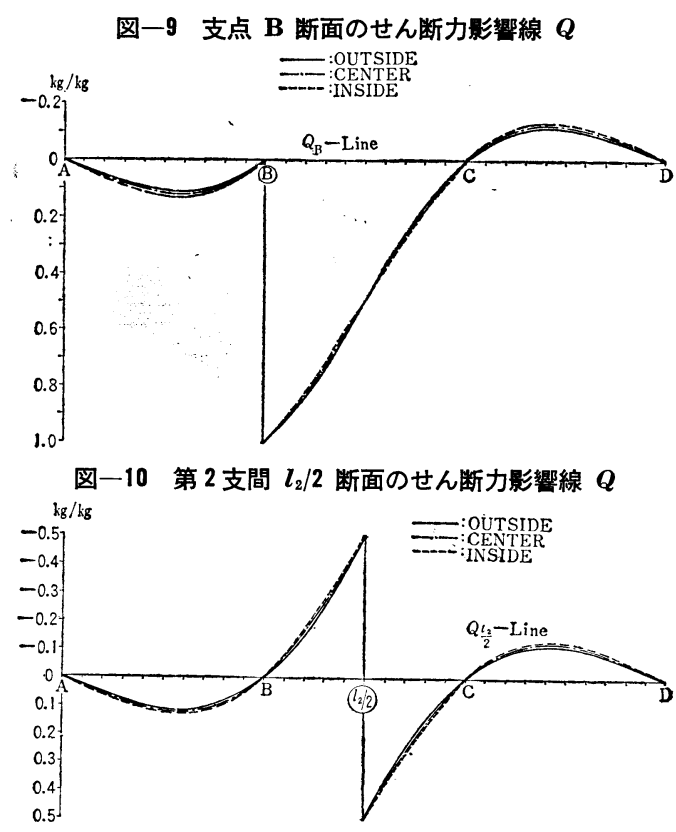

図一11に側スパンの中央断面における曲げモーメン ト $M_{y}$ の影響線を示す。側スパンの直線桁部分に関し ては直線連続析の曲げモーメント影響線に全く似てい る。とてろが中央スパンにおいては曲率の影響によって 外桁側載荷の方が大きくでている。

図一11 第 1 支間 $l_{1} / 2$ 断面の曲げモーメント影響線 $M_{y}$

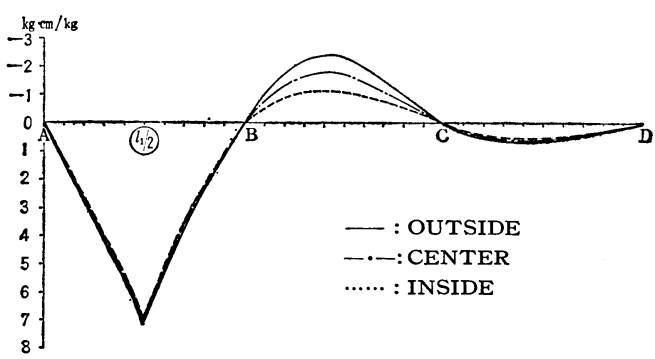

図一12 に側スパンの 中央断面における曲げねじりモ 一メント $M_{w}$ の影響線を示す。中央スパン断面のとき と同じように外桁側載荷と内桁側載荷とで符号が逆にな る。そして絶刘值はほぼ相等しい。また中央断面から離 れるにつれて減衰がはなはだしい。そして隣のスパン上 の荷重の影響がほとんどない。軸線上載荷の場合にねじ りの効果が現われないのは, 問題の断面が直線桁上にあ るためだと考えられる。 
図一12 第 1 支間 $l_{1} / 2$ 断面の曲げねじりモーメント $M_{w}$ 影繁線

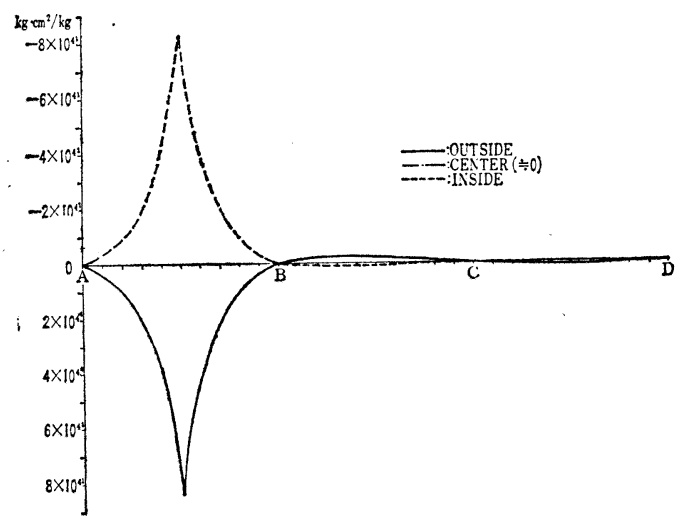

图-13 第 1 支間 $l_{1} / 2$ 断面の St. Venant ねじりモーメント $T_{s}$ 影望線

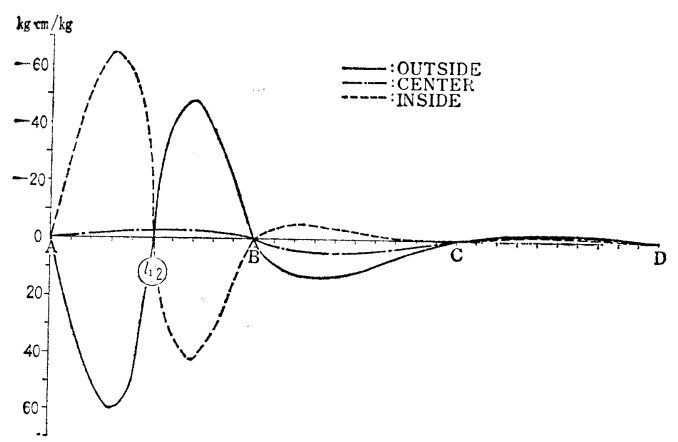

図一14 第 1 支間 $l_{1} / 2$ 断面の 2 次ねじりモーメント $T_{w}$ 影梅線

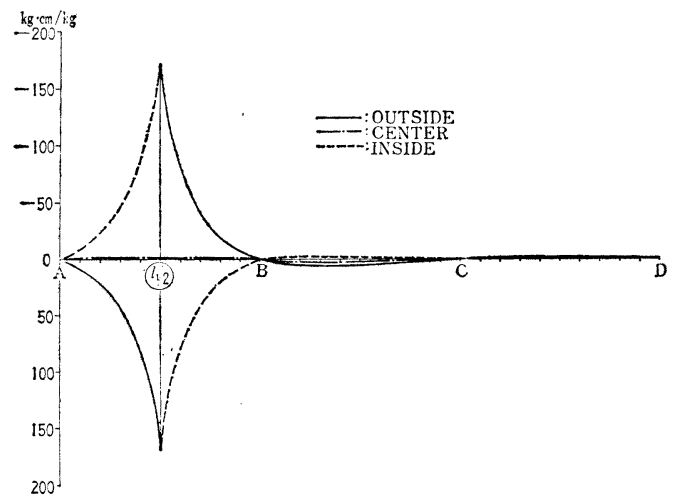

図一13，14 にはそれぞれ側スパン中央断面における St. Venant ねじりモーメントおよび 2 次ねじりモーメ ントの影響線を示す。いずれも中央断面の両側でねじり の効果が逆に現われる。前者においでは, 端支点 $\mathrm{A}$ 側の 縦距が中間支点 $\mathrm{B}$ 側の縦距より大きく，乙の相違は中間 支点上の拘束のためだと考えられる。また曲線部分 $\mathrm{BC}$ 間載荷の場合にも若干影響がある。後者においては, 側 スパンを直線単純桁とした場合のものと類似している。 隣接スパン載荷の影響はほとんどなく減衰は急激であ る。

図一15 17 にはそれぞれ 側スパンの支点 $\mathrm{A}$, 中央断
図-15 支点 A 断面のせん断力影敏線 $Q$

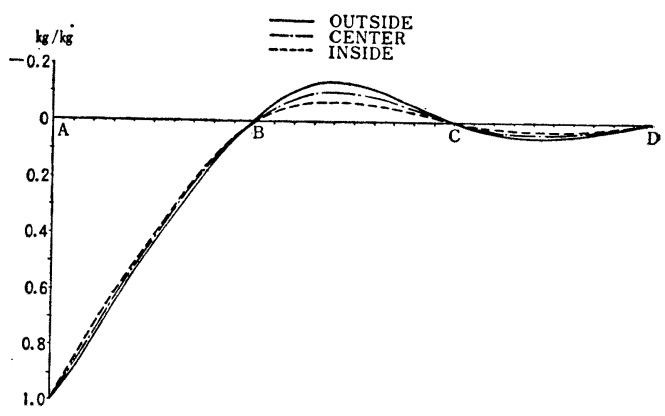

図一16 第 1 支間 $l_{1} / 2$ 断面のせん断力影蹈線 $Q$

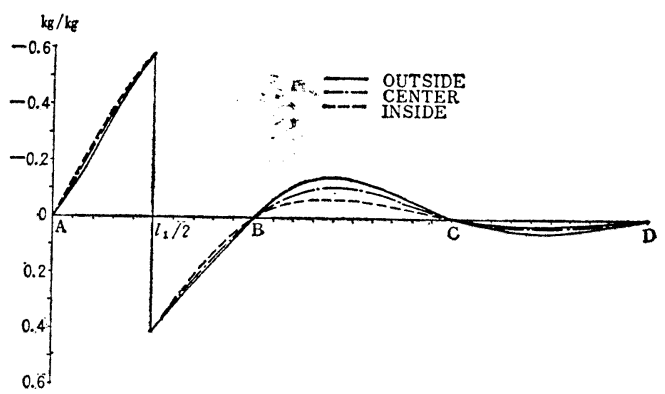

図-17 支点 B 断面のせん断力 $Q_{1}$ 影帮線

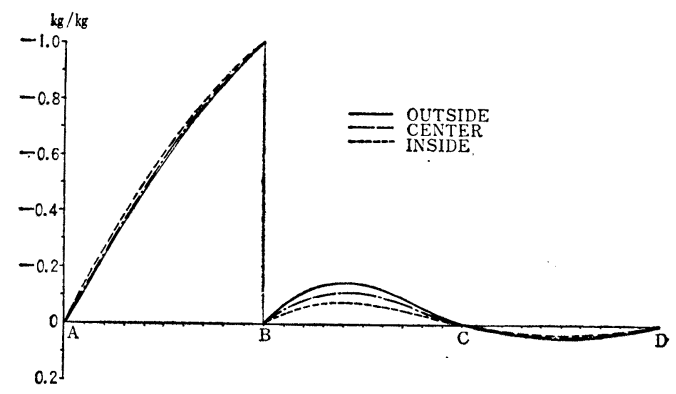

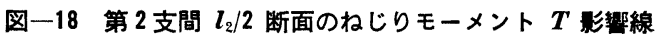

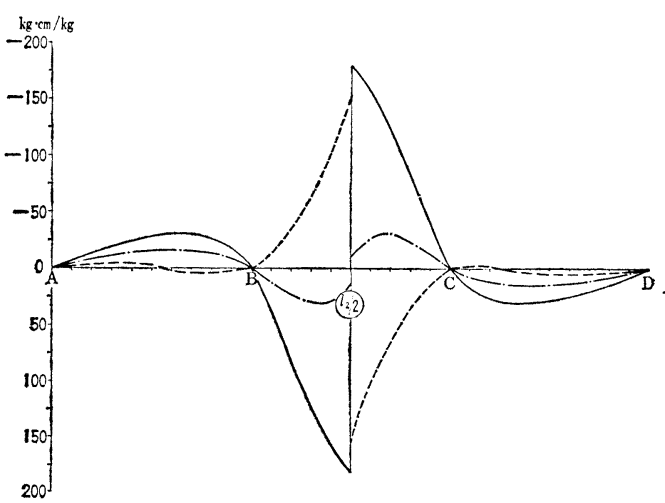

面, 支点Bにおけるせん断力 $Q$ の影響線を示す。側ス パンでは直線連続枌のせん断力影響線とほとんど変わら ない。中央スパンにおいては, 曲線部のため, 偏心の影 響が認められる。

図一18，19にはそれぞれ中央スパン中央断面および 側スパン中央断面における合ねじりモーメント $T$ の影 


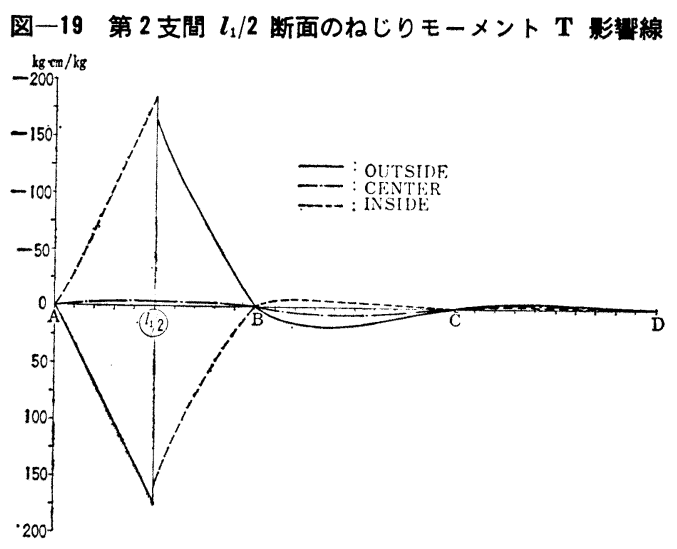

響線を示す。前者において，中央断面の両側で逆対称で ある。全体的に曲線分布で変化するが, その点が直線連 続析の場合と異なる。側スパン外行側載荷においてもか なり影響がみられる。後者については, 側スパン載荷で はほぼ直線状に変化している。すなわち直線連続析とほ とんど相違せず, 中央スパンでわずかに曲線の影響が現 われている。

\section{(2) 変形量の影揰線}

図一20 には中央スパンの中央断面のたわみ $\delta$ の影響 線を示す。もちらん中央断面の両側に対称である。中央 スパンでは外桁側載荷の場合が内桁側載荷の場合の約 2 倍のたわみを生ずる。側スパンに載荷する場台には偏心 の影響は顕著でない。

図一21 には中央スパンの中央断面の回転角 $\beta$ の影響 線を示す。中央スパン載荷の場合には， $\beta$ は負值をと

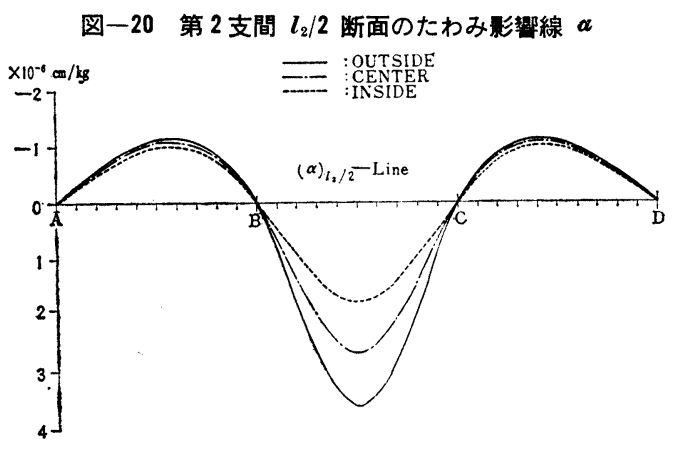

図-21 第 2 支間 $l_{2} / 2$ 断面の回転角影稫線 $\beta$

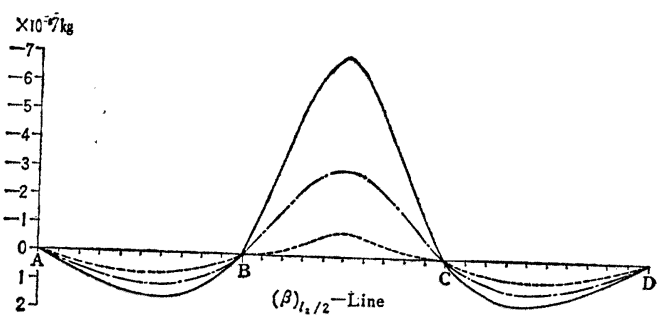

ろ。とれは外析側が内桁側より以上に鉛直下方に変位す るような方向に断面が回転するととを意味する。両側ス パンに載荷する場合にはその逆向きに回転する。いずれ の場合にも偏心の影響がはっきり現われ，乙とに中央ス パン載荷において外析側載荷の際には回転角は非常に大 きい。内側載荷でも外方へ回転するととは曲率が大きい 本橋の特性であると考えられる。

\section{9. 結言}

(1) 連続曲線析橋について, 支点曲げモーメントおよ び支点曲げねじりモーメントに関する弾性方程式を誘導 した。

(2) 連続曲線析橋の任意断面における断面力および変 形量の解を与えた。

(3) ある連続曲線桁橋に関して, 断面力および変形量 の影響線を描き，その静力学的特性を明確にできた。

最後に本数值計算例は京都大学大学院山川純雄君のご 尽力に負うところ大であって, 同君に対し厚く感謝申し 上げる次第である。

\section{参考 文 献}

1）小西一郎・小松定夫 : 曲線箱杕橋の 立体的応力解析, 第 15 回土木学会年次学術講演会講演概要第 II部, p. 7, 昭和 35 年 5 月

2）小西一郎・小松定夫：連続曲線桁橋の立体的解析, 昭和 35 年度土木学会関西支部年次学術講演会講演概要, p. 34 昭和 35 年 11 月

3）小西一郎・小松定夫 : 薄肉曲線桁の 基礎理論, 土木学会 論文集第 87 号, 昭和 37 年 11 月

4）小西一郎・小松定夫 : 単純曲線析橋の立体的解析, 土木 学会論文集第 90 号, 昭和 38 年 2 月

(原稿受付 : 1962.7.17) 


\title{
THREE DIMENSIONAL STRESS ANALYSIS FOR CONTINUOUS CURVED GIRDER BRIDGE
}

\author{
By Dr. Eng., Ichirō Konishi C.E. Member and Dr. Eng., Sadao Komatsu, C.E. Member
}

\section{SYNOPSIS}

For the continuous curved girder bridge under the vertical loads, the three dimensional stress analysis is presented on the basis of the torsion bending theory.

In a continuous curved girder bridge having a number of spans, the cross sectional quantities as well as the principal dimensions will generally differ from those in adjacent span and it is a statically indeterminate structure. For the sake of analysis, the simply supported system will be produced by cutting the structure at each intermediate supports $m$. Then both the bending moments $M_{m}$ and the warping moments $\mathfrak{M}_{m}$ that must be applied at the cross sections in order to close the gaps and restore continuity are the statical redundancies of the problem. From the condition of continuity, the theorem of least work leads to a set of elastic equations (11) for the unknown stress resultants $M_{m}$ and $\mathfrak{M}_{m}$.

The coefficients $a, b$ and $d$ contained in the equations can be easily determined by the formulas (12) to (49), and also the load terms $L_{m}$ and $N_{m}$ are given by the formulas (50) to (98) for some typical loading conditions.

Solving these equations to find the magnitudes of the unknown quantities and adding the contributions due to the end moments $M_{m}, \mathfrak{M}_{m}$ and due to the applied loading upon the imaginary simply supported system, the final stress resultants, namely, the bending moment $M_{y m}$, the warping moment $M_{w m}$, the St. Venant's torsional moment $T_{s m}$, the secondary torsional moment $T_{w m}$, the shear force $\bar{Q}_{m}$ due to bending and the total torsional moment $T_{m}$, of the $m$ th span can be readily evaluated from the expressions (5) to (10). Hence stress distribution at any cross section can be clarified by means of the formulas (51) and (53) given in reference (3).

Similarly the deformation, namely, the deflection $\delta_{m}$ of the shear center and the rotating angle $\beta_{m}$ about the same point at any cross section are given by (128) and (129) respectively.

A three-equal-span continuous curved girder bridge with the same constant section as King County shown in Fig. 2 are treated as a numerical example of the foregoing analysis.

From these results of the estimation, the influence lines of the stress resultants and the deformations at some selected cross section are illustrated in Fig. 3 to 21.

Thus the effects of the curvature upon the basic characteristic in the continuous curved bridge can be explicitly seen by examining of all the data obtained in this paper.

(Recreved July 17, 1962) 